\title{
Testing the effectiveness of integrating community-based approaches for encouraging abandonment of female genital cutting into CARE's reproductive health programs in Ethiopia and Kenya
}

Jane Chege

Population Council

Ian Askew

Population Council

Susan Igras

Jacinta Muteshi-Strachan

Follow this and additional works at: https://knowledgecommons.popcouncil.org/departments_sbsr-rh

Part of the Community-Based Research Commons, International Public Health Commons, Maternal and Child Health Commons, Medicine and Health Commons, Obstetrics and Gynecology Commons, Public Health Education and Promotion Commons, and the Women's Health Commons How does access to this work benefit you? Let us know!

\section{Recommended Citation}

Chege, Jane, Ian Askew, Susan Igras, and Jacinta Muteshi-Strachan. 2004. "Testing the effectiveness of integrating community-based approaches for encouraging abandonment of female genital cutting into CARE's reproductive health programs in Ethiopia and Kenya," FRONTIERS Final Report. Washington, DC: Population Council. 


\section{Testing the Effectiveness of Integrating Community-Based Approaches for Encouraging Abandonment of Female Genital Cutting into CARE's Reproductive Health Programs in Ethiopia and Kenya}

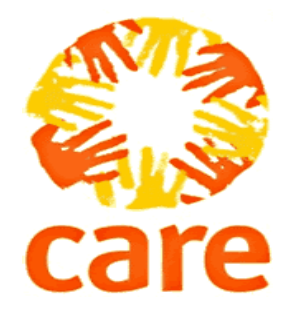

(2) Population Council FRONTIERS IN REPRODUCTIVE HEALTH

USAID 


\section{Testing the Effectiveness of Integrating Community-Based Approaches for Encouraging Abandonment of Female Genital Cutting into CARE's Reproductive Health Programs in Ethiopia and Kenya}

FRONTIERS in Reproductive Health Jane Chege Ian Askew
CARE International Susan Igras

Jacinta K. Muteshi

This study was funded by the U.S. AGENCY FOR INTERNATIONAL DEVELOPMENT (USAID) under the terms of Cooperative Agreement Number HRN-A-00-98-00012-00 and Population Council In-house project number 5804 13028, and CARE Cooperative Agreement Number HRN-A-00-98-00023-00. The opinions expressed herein are those of the authors and do not necessarily reflect the views of USAID. 


\section{ACKNOWLEDGEMENT}

Many people contributed to the research and interventions that form the basis of this report. Two individuals require specific mention, Dr. Omondi-Odhiambo, the Principal Researcher who was in-charge of the baseline and endline survey data collection and analysis in Kenya, and Mr. Amare Dejene, the Principal Researcher who performed a similar role in Ethiopia.

In addition, without the program staff who worked on the actual integration of FGC abandonment efforts, there would have been no operations basis for the study. Key people involved in conceptualising and moving forward the integration and operations research effort include Mr. Asmelash Woldemariam and his project staff in CARE-Ethiopia as well as Ms Saida Ali and her program staff at both CARE-Kenya and the National Council of Churches of Kenya, operating in the Dadaab Refugee Camps.

We would also like to express great appreciation to our colleagues from the FRONTIERS Program in Nairobi and Washington and USAID Washington for their review, feedback, and suggestions that helped to advance the content of this report.

Finally, we would like to acknowledge those unnamed but equally critical community leaders and groups involved in the FGC abandonment activities. It is these people who extended the project-community interface to a level where communities themselves became involved in the debate and discussion around FGC. 


\section{TABLE OF CONTENTS}

Acknowledgement ........................................................................................................................................ iii

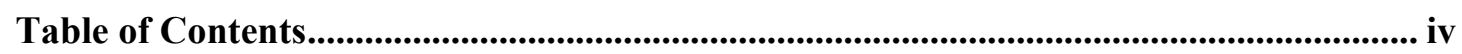

List of Tables..................................................................................................................................... vi

List of Figures ........................................................................................................................ vii

Abbreviations and Acronyms............................................................................................................. viii

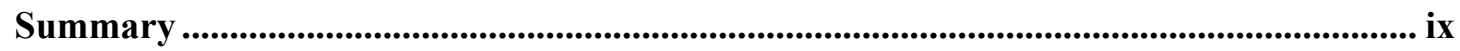

Section 1: Introduction .................................................................................................... 1

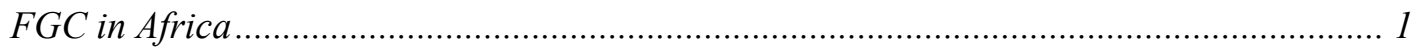

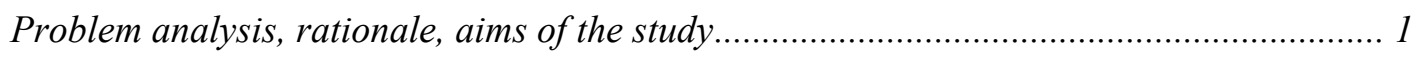

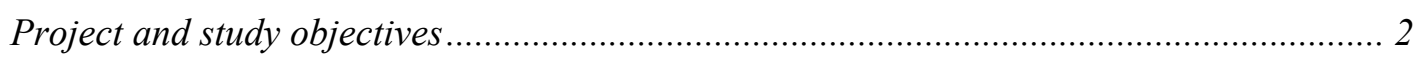

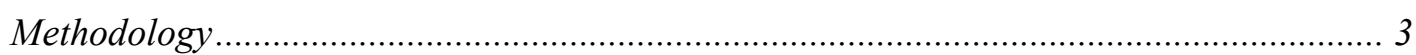

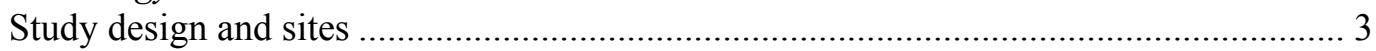

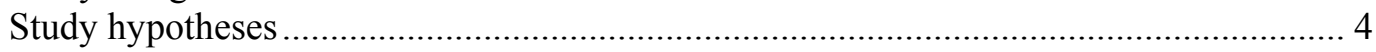

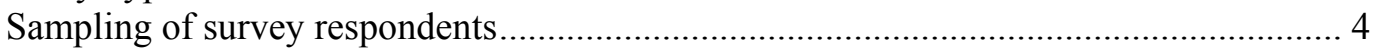

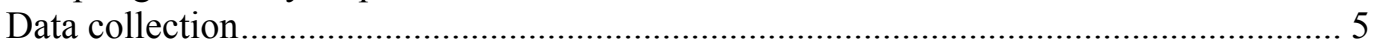

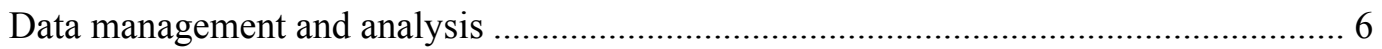

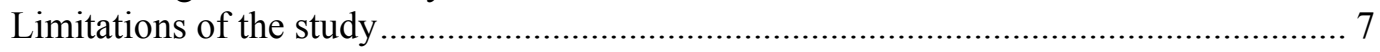

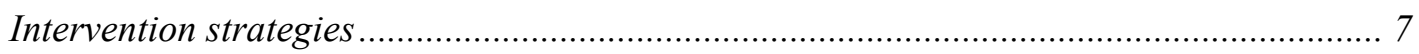

Section 2: Findings - Characteristics of respondents, attitudes, and Practices associated

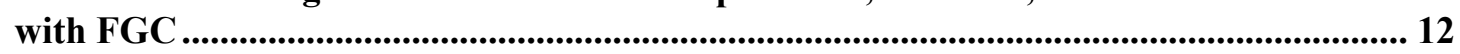

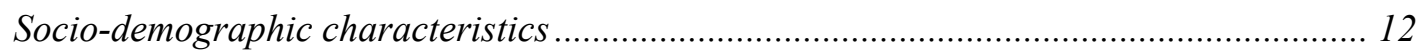

Comparability of intervention populations to control/comparison populations at baseline

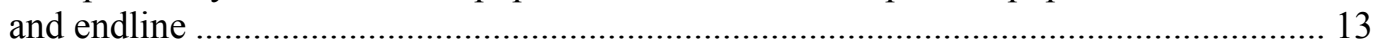

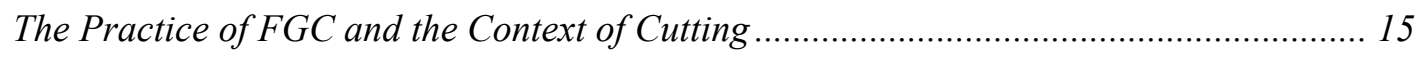

Exposure to Intervention Messages and Activities .......................................................... 16

Exposure to Anti-FGC Messages ................................................................................ 16

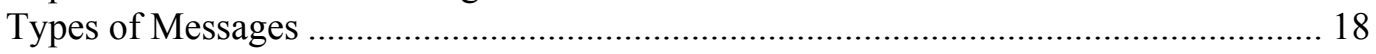

Sources of Anti-FGC Messages ................................................................................. 19

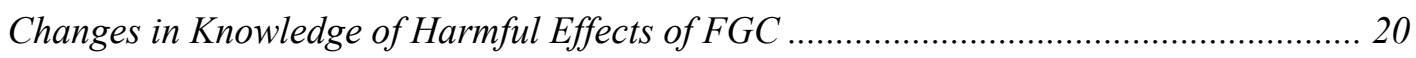

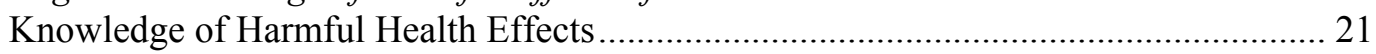

Knowledge of Harmful Psychosexual Effects............................................................. 22

Knowledge of Harmful Social Effects .......................................................................... 23

Effect of Socio-demographic Characteristics on Knowledge of Harmful Effects of FGC23

Changes in attitudes and beliefs associated with FGC ................................................. 24

Beliefs related to fulfillment of human rights ............................................................ 24

Effects of socio-demographic characteristics on the beliefs that FGC is a human rights

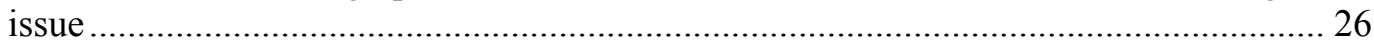

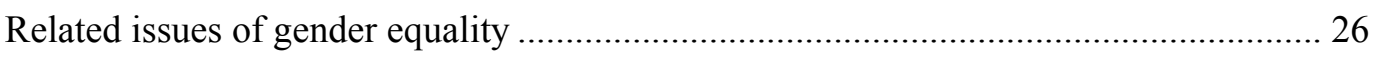

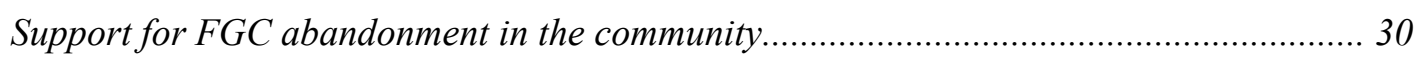

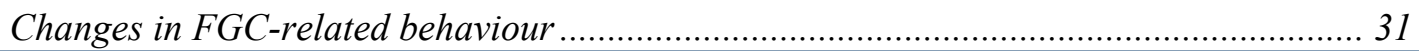


Future intention to continue the practice with one's daughters

Summary, Conclusions, and Recommendations........................................................................... 33

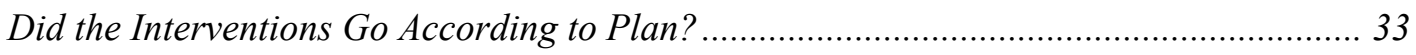

Did the Interventions Result in Expected Increases in Knowledge, Attitude and, Intended

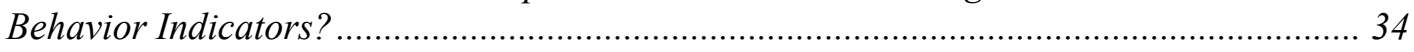

Was Collective Action Against the Practice Beginning to Occur by the End of the

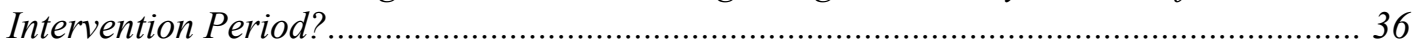

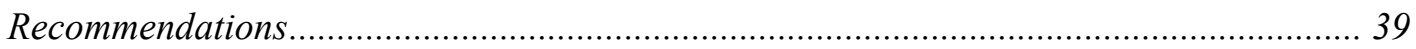

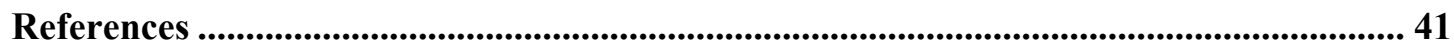

ANNEX 1: Description of key activities and selected outputs in Ethiopia and Kenya ... 43

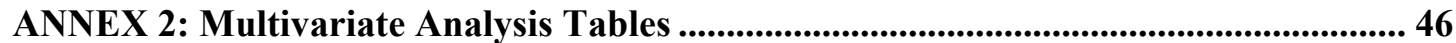




\section{LIST OF TABLES}

TABLE 1.1

TABLE 2.1

TABLE 2.2

TABLE 2.3

TABLE 2.4

TABLE 2.5

TABLE 2.6

TABLE 2.7

TABLE 2.8

TABLE A2.1

TABLE A2.2

TABLE A2.3

TABLE A2.4

TABLE A2.5
Achieved study sample sizes by study and comparison populations, and by gender

Comparison of selected socio-demographic information at baseline, by study and control/comparison group and by gender in Kenya and Ethiopia

Comparison of selected socio-demographic information at endline, by study and control/comparison group and by gender in Kenya and Ethiopia

Comparison of circumcision status and the practice of cutting in Ethiopia and Kenya as reported by female respondents at baseline

Exposure to educational messages by age in Ethiopia and Kenya

Recall of type of messages exposed to in Kenya at endline

Comparison of changes in mean knowledge scores of negative FGC effects between intervention and control/comparison sites

Comparison of differences in mean knowledge scores of all negative FGC effects by socio-demographic characteristics

Proportion of respondents agreeing with statements on equality between sexes, and mean score of "positive" gender equality responses

Results of the multiple linear regression model for mean knowledge scores of all harmful FGC effects in Ethiopia and Kenya

Results of the multiple logistic regression model for the attitude that FGC violates rights of women in Ethiopia and Kenya

Results of the multiple logistic regression model for the attitude that FGC violates rights of girls in Ethiopia and Kenya

Results of the multiple logistic regression model for the attitude in support of FGC abandonment in Ethiopia and Kenya

Results of the multiple logistic regression model for the intention not to cut their daughters in the future in Ethiopia and Kenya 


\section{LIST OF FIGURES}

FIGURE 1.1 Operational framework of CARE's multi-country FGC abandonment project

FIGURE 2.1 Percentage of respondents exposed to anti-FGC messages

FIGURE $2.2 \quad$ Percentage of respondents who did not know any negative FGC effects

FIGURE 2.3 Percentage of respondents who did not know any negative health FGC effects

FIGURE 2.4 Percentage of respondents who did not know any negative psychosexual FGC effects

FIGURE 2.5 Percentage of respondents who stated that FGC violates women's rights

FIGURE 2.6

Percentage of respondents stating that FGC violates girls' rights

FIGURE 2.7 Proportions of respondents who supported FGC abandonment in Ethiopia and Kenya

FIGURE 2.8 Proportions of respondents who do not intend to cut their daughters in the future in Ethiopia and Kenya 


\section{AbBreviations AND ACRONYMS}

\begin{tabular}{|c|c|c|}
\hline AIDS & - & Acquired Immune Deficiency Syndrome \\
\hline AR & - & Alternative Rite \\
\hline $\mathrm{BCC}$ & - & Behavior Change Communication \\
\hline DHS & - & Demographic and Health Survey \\
\hline FGC & - & Female Genital Cutting \\
\hline FGDs & - & Focus Group Discussions \\
\hline FP & - & Family Planning \\
\hline HIV & - & Human Immunodeficiency Virus \\
\hline IEC & - & Information, Education, and Communication \\
\hline KDHS & - & Kenya Demographic and Health Survey \\
\hline $\mathrm{MH}$ & - & Maternal Health \\
\hline NCCK & - & National Christian Council of Kenya \\
\hline OR & - & Operations Research \\
\hline PATH & - & Program for Appropriate Technology in Health \\
\hline PHC & - & Primary Health Care \\
\hline RH & - & Reproductive Health \\
\hline TBAs & - & Traditional Birth Attendants \\
\hline UNHCR & - & United Nations High Commission for Refugees \\
\hline WHO & - & World Health Organization \\
\hline
\end{tabular}




\section{SUMMARY}

Between 2000 and 2002, CARE International, with technical support from the Frontiers in Reproductive Health Program of the Population Council, implemented an operations research (OR) project among the Afar people of Ethiopia and Somali refugees in Daadab camps in Kenya. The OR project aimed to assess the effectiveness of community-based female genital cutting (FGC) strategies in increasing the knowledge of harmful FGC effects and positive FGC related attitudes and intended behaviour among the intervention communities. Both communities are predominantly of Islamic faith and practice infibulation, the most severe form of FGC. In both Ethiopia and Kenya, CARE integrated FGC interventions into existing community-based reproductive and primary health care information and service delivery activities.

The study in Ethiopia was designed to test the effectiveness of education activities using behaviour change communication (BCC) approaches and advocacy activities by religious and other key leaders in the intervention site. No interventions occurred in the control sites. In Kenya, both the intervention and comparison sites had education/BCC activities. The intervention site had advocacy activities in addition to education/BCC activities. The OR study assessed the effectiveness of BCC and advocacy activities versus no interventions in Ethiopia, while in Kenya the comparison was between BCC strategies alone and the combination of BCC and advocacy activities.

Results of the analysis indicate that in both countries, the intervention strategies were very effective in increasing knowledge of negative FGC effects and exposure to anti-FGC messages. The focus on increasing knowledge of social and psychosexual effects and viewing FGC as a human rights rather than a health issue only paid off. The highest increase in knowledge was in social effects followed by psychosexual effects. There also was a significant increase in the proportions of respondents who expressed the view that FGC violates the human rights of women and girls.

In Ethiopia, the increased knowledge of harmful FGC effects and human rights issues translated to a positive attitude in support of FGC abandonment and an intention not to cut their daughters in the future (used as a proxy for behaviour change). The intervention site witnessed more than a hundredfold increase in proportions of respondents expressing support for FGC abandonment and an intention not to cut their daughters in the future. In Kenya, the analysis indicated mixed results in attitude and intended behaviour change. Men slightly increased their support for FGC abandonment and an intention not to cut their daughters in the future, while women's support for both indicators decreased between the baseline and endline surveys in both the intervention and comparison sites. Further, the increase in support for FGC abandonment and an intention not to cut their daughters was significant in the comparison, but not the intervention, site.

There were significant gender differences in response to the interventions in both Ethiopia and Kenya. The magnitude of change in mean knowledge scores was higher amongst women than men. Higher proportions of men supported the view that FGC violates the rights of women and girls, supported FGC abandonment, and expressed an intention not to cut their daughters in the future. The magnitude of positive change between baseline and endline surveys in these indicators was larger amongst men than women. In addition, men had higher mean scores in positive gender equality indicators.

It appears the interventions were more successful in Ethiopia than Kenya. In all the knowledge and attitude indicators assessed, the Ethiopia intervention site had a higher magnitude of positive change than Kenya. In Kenya, it is not clear if the advocacy strategy added much value to the intervention. Apart from an increase in knowledge of the harmful effects of FGC, where the intervention site had a significantly higher magnitude of change, the comparison site performed better on all attitude and intended behaviour indicators. This poorer performance of 
the intervention site in Kenya is partly attributed to the failure to implement the advocacy strategy effectively.

Although not quantitatively measured in this study, project staff and community members (the latter as evidenced from the focus group discussions held at endline) started to witness social changes. In both countries, there was active public debate on the merits of continuing the practice and some uncut girls, men and women, and families were publicly stating that they did not want to continue the practice. In both countries, traditional leaders had to begin to address the issue of protection of those wishing to remain uncut, an area of adjudication never-before addressed. In Kenya, support groups were formed of those who did not want to succumb to cutting. In Ethiopia, collective action was beginning to be observed; 70 elders from intervention and control villages made open declarations that their villages would henceforth not cut their daughters. 


\section{SECTION 1: INTRODUCTION}

\section{FGC in Africa}

In absolute numbers alone, the practice of female genital cutting (FGC) affects more than 130 million women and girls worldwide, most of whom live on the African continent. This global number hides the many variations observed in the practice. Widely differing forms of cutting are done ${ }^{1}$ in a variety of social and cultural contexts. The practice is more often associated with distinct ethnic groups, rather than nations or religions, socio-economic, or educational levels. For example, Ethiopia and Kenya, the two countries in which the current research was conducted, have national FGC prevalence rates of 76 percent and 34 percent, respectively (NCTPE, 1998 and Kenya DHS, 2003). Yet, these national statistics do not reveal the magnitude of FGC among certain ethnic groups; for example in Kenya, almost all women of reproductive age group have undergone various types of FGC among the Somali (97\%), Kisii (96\%) and Maasai (94\%) ethnic groups (KDHS 2003). In baseline studies conducted in the study sites discussed in this report, the Afar community of Ethiopia reported a prevalence of 91 percent of women over 16 years and the Somali community in Kenya reported a prevalence of 100 percent.

The culturally condoned, traditional practice of FGC continues despite its harmful health and social consequences. From a purely health perspective, cutting can lead to immediate, postsurgery complications, such as haemorrhaging and infection. The more severe forms of cutting, such as infibulation, can lead to more long-term effects, such as prolonged labour and socially debilitating conditions, such as malodorous urine retention (Jones, H. et al 1999, Morison L. et. al 2001, Rainbㅇ. 1995). From a psychosexual perspective, cutting can lead to painful or difficult sexual relations and resulting problems between couples. From a social perspective, cutting can lead to situations where girls are married early, as they have symbolically begun to transition to adulthood, and subsequently lose education and income opportunities. Under these conditions, women's and girls' basic human rights to good health, to be equal partners in development, and to attain a high standard of living are compromised. Yet, even with knowledge of the harmful consequences, the practice continues to be valued for a variety of culturally "good" reasons, which contribute to people's social standing and ultimately, the social fabric of a community. In the study sites discussed in this report, values expressed included maintaining culture and traditions, ensuring fertility, conferring respect upon the girl and her family, being a devout Moslem, and ensuring the marriageability of girls and their possibilities of fulfilling lives as mothers and responsible wives.

\section{Problem analysis, rationale, aims of the study}

Interest in FGC by donor, research, and implementing agencies has increased since international activism in the 1990s framed the practice as a human rights and gender violence issue and not only a health issue. Subsequently, there is a growing body of program and research experiences that take a more holistic approach to FGC abandonment (WHO, 1999, TOSTAN, 1999). Indications exist that there is also a community preoccupation to address the issue. CARE's experiences in north-eastern Africa in conducting participatory

\footnotetext{
${ }^{1}$ WHO has developed three main categories of FGC. Type I, or clitoridectomy, often referred to as "Sunna," involves the partial or total removal of the clitoris. Type II, often referred to as excision, involves the partial or total removal of the clitoris and labia minora. Type III, often called infibulation or Pharaonic circumcision, involves excision of the entire clitoris, some parts or all of the labia minora and some or all of the labia majora. What tissue remains is stitched together, leaving a very small vaginal and urethral opening.
} 
assessments with communities to identify and prioritise reproductive health issues have shown that FGC is viewed by many women as critical. In many community groups that participated in the assessments, it was considered the number one women's health issue (Kambou, et al 1997, Igras 1999, Kambou, et al 1998).

Much of the research and evaluation work on FGC has occurred at levels of policy advocacy by integrating FGC-related services into clinical service delivery and defining the extent of the problem. There is less evidence of what works at a community level and, consequently, better practices are only now emerging to address the many program challenges inherent in working to change a social norm that has health, psychosexual, social, and rights consequences. What makes this operations research (OR) study unique from other FGC projects that have been systematically studied is its context. The evaluation literature to date on community-based programs has been focused in areas where less severe forms of cutting are practiced and in contexts where FGC is not a universal norm (Chege, J. et. al 2001, Abdel Hadi, A. 1997, Nafissatou J. et. al. 2003). The current study focuses its FGC abandonment activities in conservative, traditional populations where infibulation, the most severe form of FGC, is universally practiced and where FGC has strong, yet erroneous, linkages to a religion (Islam). The OR project aimed to contribute to the literature to help inform future program designs of FGC abandonment activities operating at community levels.

\section{Project and study objectives}

The goal of this multi-country FGC abandonment project was to increase the interest and ability of communities, NGOs, and the Ministry of Health (MOH) and other local Ministries to address FGC issues appropriately and effectively. The concurrent study objective was to increase understanding of the effectiveness of different community-based interventions to reduce the practice of FGC. 


\section{Methodology}

\section{Study design and sites}

Study sites. The study was conducted in semi-arid rural areas in Ethiopia and Kenya ${ }^{2}$. (See maps.) The intervention sites were part of project areas reached by on-going communitybased reproductive health $(\mathrm{RH})$ projects in development and relief settings supported by CARE International and its partner agencies.

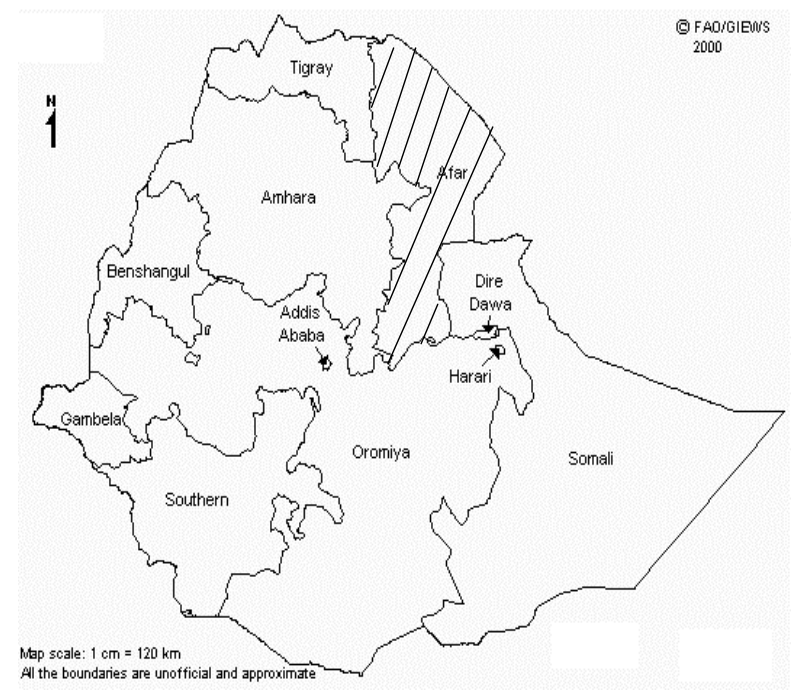

In Ethiopia, CARE joined with the Ministry of Health to add FGC abandonment and other RH services in family planning (FP), HIV/AIDS, and maternal health $(\mathrm{MH})$ to existing primary health care (PHC) services targeted to the Afar people. The Awash $\mathrm{PHC} / \mathrm{RH}$ project, located near Awash town about $250 \mathrm{~km}$ from Addis Ababa, reaches a pastoralist population of 18,000. The intervention site of Awash Woreda included 29 villages and has three elementary, two junior, and one secondary school, as well as one health centre and three clinics. Amibara Woreda, the control site, had twice the population (38,000 people) and was relatively better equipped with public services, including more schools (nine elementary, three junior and one secondary school) and health facilities (one hospital, one health centre and seven clinics).

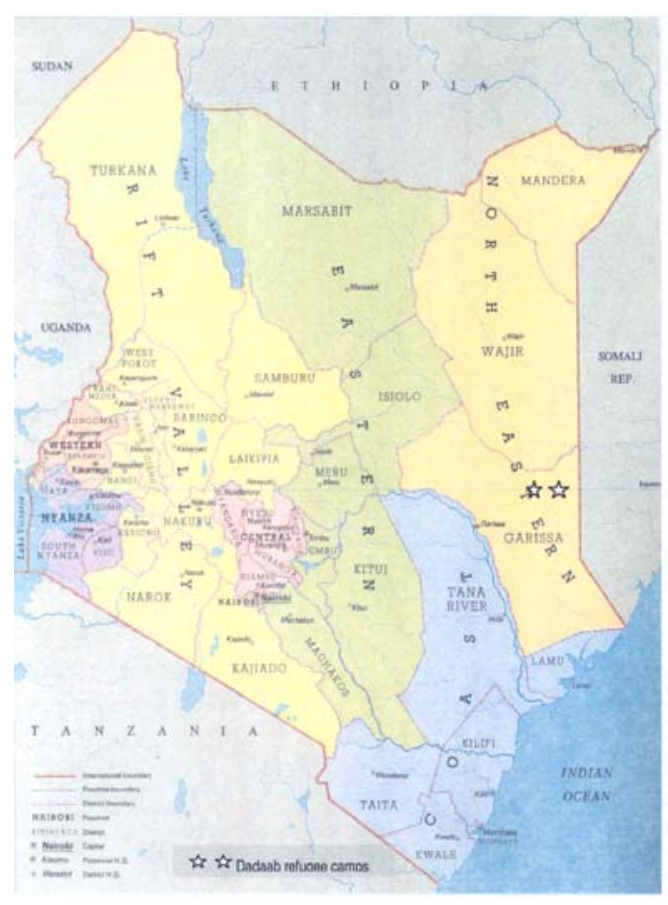

intervention site and Hagadera was the comparison site.

In Kenya, the CARE Refugee Assistance Project joined with a partner agency, the National Council of Churches of Kenya (NCCK), to expand an existing community-level RH Project. CARE operated in three refugee camps in Dadaab, situated close to the Somali border in the North-eastern Province of Kenya about $230 \mathrm{~km}$ from Nairobi and reached a population of about 123,000 people, of whom 98 percent are of Somali origin. The camps have been in operation since the dissolution of the government of Somalia in the early 1990 s. They have a rather stable refugee population and offer a variety of public services evenly distributed among the camps, including 3 hospitals, 9 clinics, and 18 health posts, as well as 6 primary schools and one secondary school. The three camps in Dadaab are geographically placed almost on a straight line in order of Dagahaley Camp (population 33,300 ), Ifo Camp (population 44,700), and Hagadera Camp (population 44,300). Ifo was the

$$
\text { intervention site and Hagadera was the companison site. }
$$

\footnotetext{
${ }^{2}$ Sudan was originally included but dropped due to challenges with the baseline survey.
} 
Study design. Using a quasi-experimental design, the intervention sites were purposively selected to correspond to CARE project areas and nearby sites were selected for comparison purposes. The actual intervention, which began with the introduction of expanded (in Kenya) and new (in Ethiopia) FGC abandonment activities, occurred over a 21-month period from January 2001 through June 2002 (in Kenya) and October 2002 (in Ethiopia).

In Ethiopia, the intervention was introduced into six villages in Awash-Fentale Woreda (hereafter called Awash) and was comprised of: 1) community-level educational outreach activities using Behavior Communication Change (BCC) approaches and 2) community level advocacy. (In addition to these community level interventions, the project also trained dispensary service providers in treating complications and counselling clients on FGC-related issues.) The control area of six villages in Amibara Woreda was located near Awash Woreda, and was an area where CARE had no operations; no FGC interventions occurred in this area. ${ }^{3}$

The study design was different in Kenya, although it too was built on education and advocacy interventions. Educational outreach activities using BCC approaches were introduced in two of the three refugee camps. Both Ifo Camp, which served as the intervention site, and Hagadera Camp, which served as the comparison camp, received the education intervention. In addition, the intervention camp received a second intervention of community-level advocacy activities.

\section{Study hypotheses}

The study was designed to evaluate the impact of different community-based strategies. The following general hypotheses were tested during the study:

- Community-level advocacy: Trained civil society entities (organizational and individual advocates) will advocate for changes in community norms, helping to lead to the reduction of FGC.

- Community-level information and education: Systematically developed and implemented information and education activities using BCC approaches will lead to increased awareness of individuals, particularly women, as decision-makers who can influence decisions regarding their daughters' being cut, helping to lead to a reduction in FGC.

In addition, country-level hypotheses were tested.

- Ethiopia: The control group population that is not exposed to IEC and advocacy interventions will have: 1) lower knowledge of negative effects of FGC, 2) less awareness of human rights as they relate to FGC, 3) be less supportive of FGC abandonment, and 4) will express less often their intention to not cut their daughters, than the intervention group population that is exposed to IEC and advocacy activities.

- Kenya: The comparison group population that is exposed to the IEC intervention alone will have 1) lower knowledge of the negative effects of FGC, 2) less awareness of human rights as they relate to FGC, 3) be less supportive of FGC abandonment, and 4) will express less often their intention to not cut their daughters than the intervention group population exposed to IEC and advocacy activities.

\section{Sampling of survey respondents}

Survey respondents included both men and women, 8 - 60 years in Ethiopia and 15-60 years in Kenya.

\footnotetext{
${ }^{3}$ In Ethiopia, the control area had no FGC interventions, thus it is referred to as a "control" group and not a "comparison" group. This is in contrast to Kenya, where both the intervention and comparison areas had interventions, but the intervention groups received an advocacy intervention in addition to education.
} 
Researchers used slightly different sampling strategies in the two countries. In Ethiopia, six sites were randomly selected in each Woreda out of the total possible number of sites/villages in that Woreda. Each site represented a cluster of smaller villages. In each village, households were randomly selected and one male and one female respondent were randomly selected per household - until the allotted number of respondents were interviewed in each site. In Kenya, all administrative "blocks" in the two refugee camps were sampled and people interviewed until the allotted number of respondents for that block was reached.

In Ethiopia, the Principal Researcher used the formula for calculating sample sizes for crosssectional surveys ${ }^{4}$. Sample size was calculated based on an assumed prevalence of 50 percent of knowledge of any harmful FGC effect and a 95 percent confidence level. This gave a sample size of approximately 200 males and 200 females per study site and a total of 800 respondents per study period.

In Kenya, the Principle Researcher used an assumed 24 percent prevalence of knowledge of any harmful FGC effect as the indicator for calculating sample sizes. Using an expected 40 percent increase in knowledge, 80 percent power, 95 percent confidence level and controlling for a 10 percent non-response rate, and design effect of 1.1, the study arrived at a sample size of approximately 360 males and 360 females in each study site and a total of 720 respondents per study period. In spite of the sensitivity of the subject of the study and the hostility faced from Somali religious leaders in one camp during the baseline survey, no refusals were registered and the study achieved a 100 percent response rate.

TABLE 1.1 Achieved study sample sizes by study and comparison populations, and by gender

\begin{tabular}{|c|c|c|c|c|}
\hline & \multicolumn{2}{|c|}{ Ethiopia } & \multicolumn{2}{c|}{ Kenya } \\
\hline & $\begin{array}{c}\text { Intervention } \\
\text { (Awash) }\end{array}$ & $\begin{array}{c}\text { Control } \\
\text { (Amibara) }\end{array}$ & $\begin{array}{c}\text { Intervention } \\
\text { (Ifo Camp) }\end{array}$ & $\begin{array}{c}\text { Comparison } \\
\text { (Hagadera } \\
\text { Camp) }\end{array}$ \\
\hline BASELINE & 407 & 412 & 720 & 720 \\
\hline Male & 205 & 208 & 360 & 360 \\
\hline Female & 202 & 204 & 360 & 360 \\
\hline ENDLINE & 400 & 400 & 720 & 720 \\
\hline Male & 213 & 200 & 360 & 360 \\
\hline Female & 187 & 200 & 360 & 360 \\
\hline
\end{tabular}

\section{Data collection}

Data collection instruments: The survey questionnaires mostly included close-ended questions. Several questionnaires were used: one to collect household level information, one for female respondents, and one for male respondents. The household questionnaire collected information on all members of the household, as well as household assets. The questionnaires designated for males and females were similar, except the women's questionnaire asked questions on her circumcision status and experiences related to her circumcision. Core assessment indicators measured changes in knowledge, attitudes, beliefs, and intended

\footnotetext{
${ }^{4}$ This sample size calculation method is not appropriate for studies seeking to assess the impact of intervention strategies. However, given the high prevalence of and magnitude of change observed in key study indicators, the sample size used was large enough to have the power to detect differences between study groups.
} 
practices (the latter as a proxy for behaviour change, since actual change was not expected after an 18 month intervention period). Core indicators focused on:

Knowledge and attitudes

- Knowledge of harmful social, psychosexual, and health effects of FGC

- Awareness of human rights that were compromised by FGC

- Support for abandonment of FGC at community and individual levels

- Intention not to cut their daughters in the future (serving as a proxy for behaviour change)

Beliefs

- Benefits of the practice

- Value of continuing the practice

- Opinions of gender equality, as it relates to decisions taken by a couple, as well as women's and girl's roles in the community.

Data collection process: In-country researchers trained local research assistants on issues related to FGC, interviewing techniques, and using the survey questionnaires. Seventeen (17) refugee women and men were selected as interviewers in Kenya and 26 local men and women were selected as interviewers in Ethiopia. The Principal Researcher in each country supervised data collection.

CARE staff conducted sensitisation activities prior to data collection in all sites and gained approval of local authorities to conduct the surveys. Informed consent was sought of all respondents before conducting interviews. Permission of parents was sought prior to interviewing minors aged below 18 years.

\section{Data management and analysis}

The Principal Researcher in each country oversaw data entry and cleaning for each of the surveys, as well as analysed the data. The two datasets were then sent to the Population Council Principal Researcher for the multi-country study, who in consultation with CARE staff, worked with the original datasets and a combined, multi-country dataset.

The OR study also included qualitative research at baseline and endline, which informed the quantitative research as well as FGC abandonment activities. At baseline, local staff and community volunteers were trained in formative research techniques using participatory learning and action approaches. Semi-structured interview guides were used in discussions to learn about the communities' views of FGC, its value and context, their understanding of negative consequences, and to gather ideas on how to facilitate community debate on the continuation of the practice. Groups that were interviewed included married men, married women, school-aged, unmarried boys and girls, practitioners, religious leaders, and community leaders. Several months later, a second series of focus group discussions (FGDs) were held using semi-structured interview guides to learn how communities defined and upheld rights and responsibilities to a good life and good health of women, men, boys, and girls, and to determine whether the notion existed that FGC could compromise a person's rights. Groups that were interviewed included married men, married women, and school-aged unmarried boys and girls. Those staff and volunteers involved in the research activities analysed the information, wrote reports (Igras S. et al, 1999; Igras S., 2000; Woldemariam, 2000; Woldemariam, 2001), and used the findings to guide the development of the FGCabandonment activities.

The FGDs that occurred at endline had a different purpose and were designed to gather information and document perceptions on social (collective) and gender related changes that were observed in communities due to the project's activities, to learn how communities 
valued the continuation of project activities, and to learn how communities viewed organizations such as CARE being involved as facilitators in a social change process. Similar types of groups were interviewed as a baseline. In Kenya, a local researcher was hired to conduct FGDs and write a report of the findings. In Ethiopia, project staff skilled in FGD research conducted the information gathering activities and reported their findings.

\section{Limitations of the study}

Readers should keep in mind the following study limitations. First, the information reported was based on self-reported behaviours and changes in attitudes and beliefs. It was not possible to confirm whether or not these reported behaviours translated into an actual reduction in female genital cutting.

The study design was contaminated in both Kenyan and Ethiopian sites, due to population movements into and out of the intervention and comparison areas. Refugees can move freely between the refugee camps in Dadaab, although not all people move between camps. Initially this was to be counteracted by having a third camp, situated between the intervention and comparison camps, to serve as a buffer. However, this changed when one of the camps refused to participate in the study, forcing the project to work in two adjacent camps.

In Ethiopia, the movements of the Afar population with their animals during the rainy season may have also put people in intervention villages in contact with people in comparison villages. In addition, early in the project implementation stage a traditional system of communication between Afar clans, the Dagu system, was "discovered" by the project staff. Information on the project and consequent community discussions was relayed to different clansmen through the Dagu system, including people in the control areas (as the survey results demonstrate).

Finally, there were some problems of consistency in collecting and entering data into databases across the two countries, making it impossible to compare several important indicators between baseline and endline and/or between countries. Information on survey clusters was not captured in data entry making it impossible to control for clustering effect in data analysis.

\section{Intervention strategies}

Over an 18-21 month period between 2001 and 2002, FGC abandonment activities were integrated into on-going, community-based health projects. As FGC abandonment activities were added, the project approaches were adjusted to be more holistic, i.e., less health focused, in order to address the social norms, beliefs, and attitudes that reinforced the continuation of the practice. The project sought to inform and educate communities on the issues and create public "spaces" "or discussion and debate, and to allow the community and influential persons/advocates to decide for themselves what position they wanted to take and why. The project facilitated individual change and supported collective action as it emerged. As the project progressed, a social change framework gradually emerged that guided the overall project activities and took into account the health, psychosexual, and social factors that influence both individuals and the larger community to choose to continue the practice, as well as efforts to support collective action as it emerged.

Four main strategies were employed by the project.

Pre-intervention: Understanding the context of the practice in order to design relevant interventions. CARE and partner agency staff and some community members conducted 
formative research at baseline, used to ensure that relevant, context-specific activities were included in the interventions.

Informing and educating communities using educational outreach strategies designed to ensure debate and public discussion, while concurrently expanding the educational messages to include social, psychosexual, and gender and human rights issues related to FGC.

Training figured prominently in the early phases of the project to ensure a common understanding, approach, and educational messages related to FGC abandonment. In Ethiopia, 469 people received training. ${ }^{5}$ Themes included FGC consequences (health, psychosexual, social), the lack of relation of religion to the practice, and the changing nature of culture. The men and women who were trained included project staff, $\mathrm{MOH}$ officials, community leaders, and youth leaders. In Kenya, 1,407 people received training. Although, similar themes were included, there was a strong focus on messages related to women's and girls' human rights. The trained men and women ranged from project staff and volunteers to members of various camp committees involved in camp management, as well as local male, female, and youth leaders.

Community education and public discussion activities occurred systematically; 12,948 people were counted as attending educational events in Ethiopia in the intervention site over the 15month period and 34,508 people $^{6}$ were counted in Kenya (in both camps). To get a general idea of the intensity of these activities, one can calculate that 1.4 events per person occurred in Awash, Ethiopia and 2.6 events per person occurred in the Ifo and Hagadera sites in Kenya. (Refer to the section on "exposure" later in this report, to see more information on who was reached by the interventions, based on information collected during the population-based surveys.)

These events and messages were delivered through a variety of channels: a) meetings held by community volunteers and extension agents with community groups, women's groups, health education groups, or in schools; b) popular theatre groups' performances that incorporated social and psychosexual issues in their scenes; c) evening video sessions that showed recorded discussions by religious leaders speaking out on FGC issues (Ethiopia only); and d) mass media activities, whereby FGC issues were linked to international events, such as international refugee day and international women's day, and as part of a violence-againstwomen campaign (Kenya only).

Supporting advocacy activities of community level advocates. Project staff systematically targeted influential people who could serve as advocates - such as religious leaders, teachers, elders and other community leaders - with activities designed to provide information, raise issues, and inform such influential leaders in order for them to advocate on issues of FGC. Specific training and messages were constructed for each group, e.g., religious leaders would speak to the erroneous association of Islam and FGC.

In Kenya, advocates were drawn from a wide variety of influential people. Over half of the people who received educational outreach training in Kenya were categorized as influential people/leaders. In Ethiopia, staff worked particularly with religious leaders, as this group of advocates was felt to be the most critical group in terms of re-defining the relationship of FGC to religious obligation, erroneously associated by much of the community including

\footnotetext{
${ }^{5}$ The training from Ethiopia and Kenya are from the project reporting system and represent simple counts of people who were trained. That is, some people may have received training several times and each time they were trained counted as one.

${ }^{6}$ As with the data presented on training, these numbers represent simple counts of attendance. They do not include those attending the Participatory Educational Theatre performances in Kenya or those hearing the educational messages through the Dagu system in Ethiopia.
} 
some religious leaders. Early in the project, staff offered to facilitate a Woreda-wide meeting of religious leaders with a resource person from the Ministry of Social Affairs and a nationally known religious leader who held the position that FGC was not mandated under Islam. CARE staff were observers to this three-day review of religious writings and interpretations of those writings. By the end of the meeting, the majority of religious leaders agreed that FGC was not required on religious grounds and that they would speak of this finding to the faithful.

Supporting collective action/social change: As community level changes began to be noted, the project helped support those who wanted to publicly commit to ending the practice, due in large part to education and advocacy interventions. Three types of support were offered, including: limited and temporary "protection" to those seeking refuge, e.g., whenever girls and families approached CARE and partner agencies to help them and working with indigenous or traditional adjudication structures and community leaders to define/redefine their traditional roles to include playing a greater protection role for women, girls, and families who chose to publicly declare themselves against the practice. Where asked, the project also provided support to groups of individuals who desired to create support groups for those feeling social pressures after taking a position of wanting to end the practice.

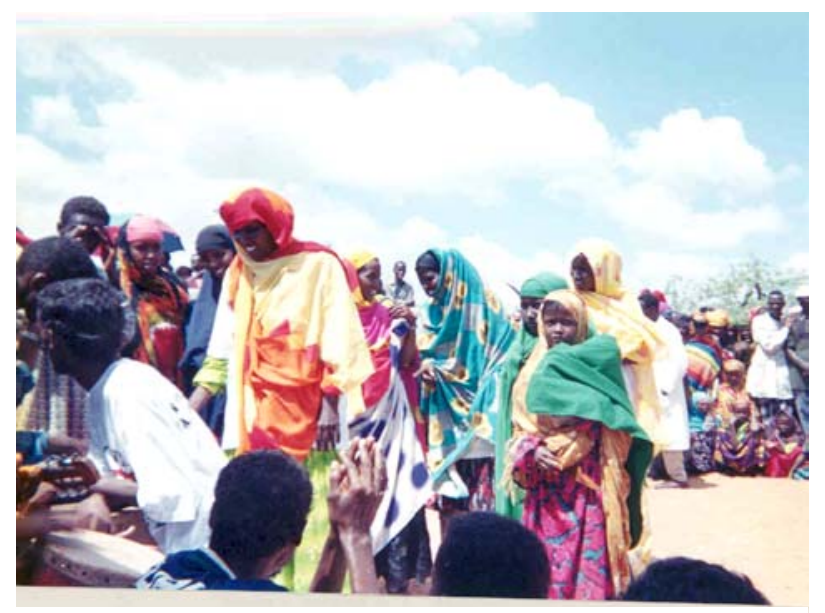

While the above interventions began during the study period, these activities actually have continued in both Kenya and Ethiopia after the study period ended, as part of the larger, ongoing RH projects. Annex 1 presents more detailed information on the approaches taken and interventions that occurred in the two study sites.

There were some notable differences in approaches to the interventions between the two sites. In Ethiopia, the project worked extensively with religious leaders. This was planned in Kenya, but never was realized during the intervention period. The project approaches to address human rights and gender differences also varied, due to the very different cultural contexts of the two sites. In Kenya, with a refugee population aware of international conventions on human and refugee rights, the project took a proactive approach to working with communities to discuss whether FGC was a violation of women's and girls' human rights. In Ethiopia, where human rights and gender issues/inequalities were known more from a traditional/religious context, the project approach was to address these issues through actions, more than through use of human rights-based messages and education activities. For example, the project ensured that there was women's participation as community health workers and on health committees to begin to build conditions that would eventually help women politically, socially, and/or collectively to play new roles in their communities.

Moving from traditional reproductive health to social and reproductive health approaches. Project staff developed a position paper to guide the process of integrating FGC into existing $\mathrm{RH}$ programs that included principles of respect, working with communities, and allowing communities themselves to decide whether they wanted the practice to continue or not. These design changes and operating principles subsequently forced a shift in implementation approaches. For example, instead of playing the role of educators with a goal of providing information, staff and volunteers also had to act as facilitators of discussions and debates. 
Project staff had to take a "back seat" role in the process, guided by a belief that it was the communities' decision whether or not to change the practice, not the project's. The project's relationship with local leaders also shifted - from coordinating to working with leaders to become advocates on FGC abandonment issues.

Even with this thoughtful planning, staff faced challenges as the information and advocacy interventions began. In a few instances, especially in Kenya, staff were actually threatened by community members because they publicly dared to bring up the subject and provide more complete information on negative health and social consequences relating to FGC. Once community reactions started to occur and individuals began to publicly come out against the continuation of the practice, the issue of protecting those being marginalized and threatened arose, and with that, the question of who had responsibility to protect these people. As community reactions to the debates and discussions began to emerge, with some people taking public positions of wanting the practice to end, a new project component was needed to support those facing social pressures to conform to the norm of cutting.

CARE's experience demonstrates that it is possible and effective to integrate FGC into community-based health projects, provided RH programs are adjusted to be more holistic in nature and that projects take into account the community context and views towards FGC as projects are designed. Several program design factors were essential to the success of the FGC abandonment activities. First, the program shifts described above could only occur in RH projects that were community-based. Facility-based programs by definition are limited in their scope of activities and ways of interacting with communities. A second critical factor was that the topic of FGC abandonment was part of a larger set of issues addressed by the RH projects. If FGC had been tackled as a stand-alone issue, and not within a larger project context such as health and social well-being, it is likely that the community would have viewed the interventions as part of an FGC abandonment agenda being imposed by outsiders. Related to this, the project position of not imposing its values on the community was likely critical. Recognition of CARE from earlier projects in the area as a "neutral" actor, with no religious or other agenda, allowed for dialogue. 


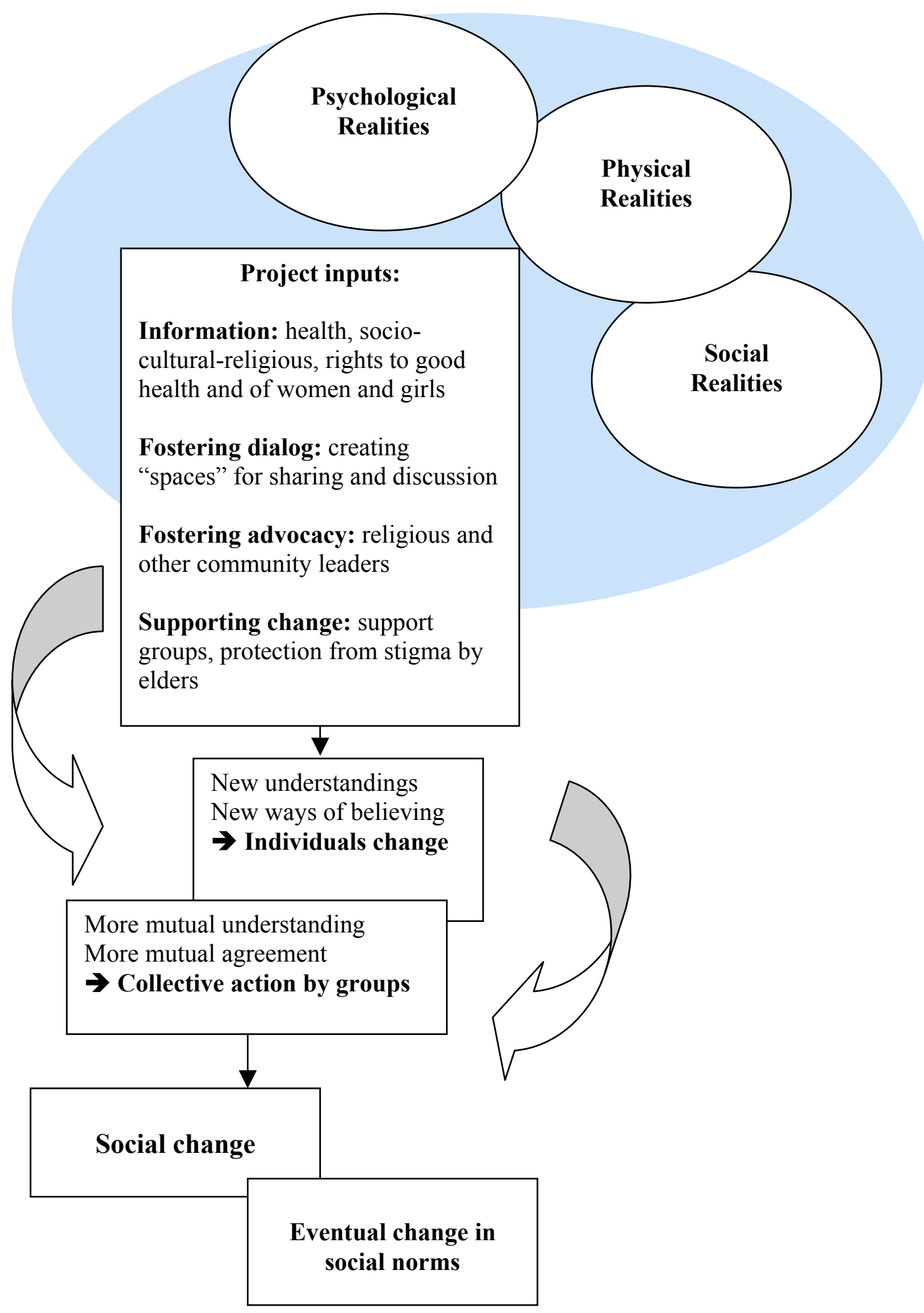




\section{SECTION 2: FINDINGS - CHARACTERISTICS OF RESPONDENTS, ATTITUDES, AND PRACTICES ASSOCIATED WITH FGC}

\section{Socio-demographic characteristics}

Respondents were asked standard socio-demographic questions on their age, education, marital status, occupation. The main findings are presented in Table 2.1 below.

TABLE 2.1 Comparison of selected socio-demographic information at baseline, by study and control/comparison group and by gender in Kenya and Ethiopia

\begin{tabular}{|c|c|c|c|c|}
\hline & \multicolumn{2}{|c|}{ Ethiopia } & \multicolumn{2}{|c|}{ Kenya } \\
\hline & $\begin{array}{l}\text { Intervention } \\
\text { (Awash) } \\
(n=407)\end{array}$ & $\begin{array}{c}\text { Control } \\
\text { (Amibara) } \\
(n=412)\end{array}$ & $\begin{array}{c}\text { Intervention } \\
\text { (Ifo) } \\
(n=720)\end{array}$ & $\begin{array}{c}\text { Comparison } \\
\text { (Hagadera) } \\
(n=720)\end{array}$ \\
\hline \multicolumn{5}{|l|}{$\begin{array}{l}\% \text { with below primary } \\
\text { level of education }\end{array}$} \\
\hline Women & 88 & 89 & 75 & $57^{\star \star \star *}$ \\
\hline Men & 71 & $80^{*}$ & 56 & 53 \\
\hline Women and men & 79 & 84 & 66 & $55^{* * *}$ \\
\hline \multicolumn{5}{|l|}{ Mean age } \\
\hline Women & 24.3 & 25.3 & 32.4 & $28.6^{* * *}$ \\
\hline Men & 27.2 & 28.3 & 32.4 & 30.4 \\
\hline Women and men & 25.8 & 26.8 & 32.4 & $29.5^{\star * *}$ \\
\hline \multicolumn{5}{|l|}{$\%$ ever married } \\
\hline Women & 57 & 65 & 75 & $58^{* * *}$ \\
\hline Men & 59 & 51 & 61 & 55 \\
\hline Women and men & 58 & 58 & 68 & $56^{* * *}$ \\
\hline
\end{tabular}

$N B: *$ denotes p-value $<0.05, * *$ denotes $p$-value of $<0.01$, and $* * *$ denotes $p$-value $<0.001$.

The Afar community in Ethiopia in this study tends to be less formally educated and younger than the Somali community in Kenya. The two groups are more similar in terms of marital status. In Kenya, women and men respondents were most often engaged in income activities on a partial or seasonal basis ( $16 \%$ of women and $17 \%$ of men). Few men $(14 \%)$ and far fewer women (4\%) had regular employment or income. More women were unemployed $(80 \%)$ than men (68\%). Occupational status was not available for Ethiopia. 


\section{Comparability of intervention populations to control/comparison populations at baseline and endline}

The socio-demographic data was also used to determine how similar or dissimilar the intervention groups were to the comparison/control groups. This information is important when interpreting changes that occurred due to the study interventions.

Comparing intervention and control populations in the Ethiopia baseline. Aside from education, the intervention and control populations are quite similar. Men from the control site had significantly lower levels of education than the intervention site. Men in both sites had significantly higher levels of education than the women, the majority of whom were illiterate. Comparing men and women, there were significantly more ever-married women than men in the control site.

Comparing intervention and comparison populations in the Kenya baseline. The comparison and intervention groups were significantly different from each other. ${ }^{7}$ The population of Ifo camp, the project's intervention site, was less educated, older, and more likely to have been or be married than the comparison site population. This is due mostly to differences seen in women respondents versus men respondents. As a group, women and men in Ifo were less educated than women and men in Hagadera, largely due to the women in Ifo being significantly less educated than women in Hagadera. Women and men in Hagadera were also significantly younger than women and men in Ifo, largely due to women in Hagadera being younger than women in Ifo. More women in Ifo have been married or are currently married than in Hagadera.

Comparing intervention and control populations in the Ethiopia endline. At endline, there were no significant differences between intervention and control groups except for education and mean age for men, with men in the intervention site being less educated and older than men in the control site. Men had significantly higher levels of education than women, the majority of whom were illiterate.

Comparing intervention and comparison populations in the Kenya endline. There were more differences than similarities. The only socio-demographic variable that was similar was marital status. There were significant differences in education levels. These differences were due in great part to women, who were less schooled than men were. Similar trends in occupation were seen at the endline for women and men as at baseline.

Baseline versus endline similarities of intervention and comparison groups in Ethiopia and Kenya. Intervention and comparison groups in Kenya remained significantly different at endline, particularly in terms of age and education with the intervention group older and more formally educated than the comparison group. When comparing the intervention and control groups in Ethiopia the groups became more different at endline than they were at baseline, particularly regarding age and education levels.

\footnotetext{
${ }^{7}$ As refugees first enter the camps, UNHCR determines where they will reside, and this has created differences in populations in the camps. For example, refugees living in Hagadera Camp have tended to come more from urban settings than those residing in other camps.
} 
TABLE 2.2 Comparison of selected socio-demographic information at endline, by study and control/comparison group and by gender in Kenya and Ethiopia

\begin{tabular}{|c|c|c|c|c|}
\hline & \multicolumn{2}{|c|}{ Ethiopia } & \multicolumn{2}{|c|}{ Kenya } \\
\hline & $\begin{array}{l}\text { Intervention } \\
\text { (Awash) } \\
(n=400)\end{array}$ & $\begin{array}{c}\text { Control } \\
\text { (Amibara) } \\
(n=400)\end{array}$ & $\begin{array}{c}\text { Intervention } \\
\text { (Ifo) } \\
(n=720)\end{array}$ & $\begin{array}{c}\text { Comparison } \\
\text { (Hagadera) } \\
(n=720)\end{array}$ \\
\hline \multicolumn{5}{|l|}{$\begin{array}{l}\% \text { With below primary } \\
\text { level of education }\end{array}$} \\
\hline Women & 91 & 86 & 73 & $66^{*}$ \\
\hline Men & 79 & $66^{\star *}$ & 64 & 57 \\
\hline Women and men & 85 & $76^{* * *}$ & 69 & $62^{* *}$ \\
\hline \multicolumn{5}{|l|}{ Mean age } \\
\hline Women & 25.3 & 25.6 & 32.0 & 31.1 \\
\hline Men & 31.2 & $27.1^{\star *}$ & 34.8 & $32.4^{*}$ \\
\hline Women and men & 28.1 & 26.4 & 33.4 & $31.8^{*}$ \\
\hline \multicolumn{5}{|l|}{$\%$ Ever married } \\
\hline Women & 57 & 65 & 74 & 75 \\
\hline Men & 59 & 51 & 69 & 62 \\
\hline Women and men & 58 & 58 & 71 & 68 \\
\hline
\end{tabular}

$N B$ : * denotes p-value $<0.05$, **denotes $p$-value of $<0.01$, and $* * *$ denotes $p$-value $<0.001$. 


\section{The Practice of FGC and the Context of Cutting}

Table 2.3 reveals that at baseline, FGC was universal in Kenya and highly prevalent in Ethiopia. On average, Ethiopian girls were cut at a slightly higher age than their Kenyan counterparts. Infibulation was the most prevalent type of cut in both Ethiopia and Kenya.

TABLE 2.3 Comparison of circumcision status and the practice of cutting in Ethiopia and Kenya as reported by female respondents at baseline

\begin{tabular}{|c|c|c|c|c|}
\hline & \multicolumn{2}{|c|}{ Ethiopia } & \multicolumn{2}{|c|}{ Kenya } \\
\hline & $\begin{array}{c}\text { Intervention } \\
\text { Awash } \\
(\mathrm{n}=819)\end{array}$ & $\begin{array}{c}\text { Control } \\
\text { Amibara } \\
(n=800)\end{array}$ & $\begin{array}{c}\text { Intervention } \\
\text { Ifo } \\
(n=1440)\end{array}$ & $\begin{array}{c}\text { Comparison } \\
\text { Hagadera } \\
(n=1440)\end{array}$ \\
\hline $\begin{array}{l}\text { Circumcision status } \\
-\% \text { Women cut }\end{array}$ & 92 & 90 & 100 & 100 \\
\hline - \% Women with pharoanic cut & NA & NA & 85 & $72^{\star \star \star}$ \\
\hline Age at circumcision (mean) & 8.3 & $6.1^{\star \star \star}$ & 6.3 & $7.1^{* \star \star}$ \\
\hline $\begin{array}{l}\text { Reported circumcision - \% stating } \\
\text { circumciser was: }\end{array}$ & & & & \\
\hline - Traditional circumciser & 47 & 53 & 53 & $44^{* * *}$ \\
\hline- TBA & 41 & 37 & 27 & 21 \\
\hline - Doctor & 2 & 1 & 8 & 13 \\
\hline - Trained nurse or midwife & 0 & 3 & 7 & 11 \\
\hline - Grandmother & 2 & 1 & 4 & 9 \\
\hline - Other & 1 & 2 & 0 & 0 \\
\hline - Don't know or cannot remember & 3 & 2 & 1 & 2 \\
\hline $\begin{array}{l}\% \text { Being circumcised alone (i.e., } \\
\text { not in a group) }\end{array}$ & 9 & $5^{*}$ & 40 & $31^{*}$ \\
\hline $\begin{array}{l}\text { Place of circumcision } \\
\text { - Bush }\end{array}$ & 76 & 84 & 9 & 9 \\
\hline - Own home & 17 & 10 & 62 & 56 \\
\hline - Another home & 1 & 2 & 12 & 13 \\
\hline - Home of practitioner & 1 & 2 & 9 & 12 \\
\hline - Hospital & 0 & 1 & 8 & 10 \\
\hline - Other/don't know & 5 & 1 & & \\
\hline Instruments used to cut & & & & \\
\hline - Own razor & 64 & $59^{*}$ & 83 & $66^{* * *}$ \\
\hline - Shared razor & 5 & 4 & 4 & 16 \\
\hline - Scalpel & 19 & 23 & 2 & 6 \\
\hline - Knife & 2 & 5 & 7 & 1 \\
\hline - Scissors & 2 & 7 & 5 & 11 \\
\hline - Don't know/other & 8 & 2 & 0 & 1 \\
\hline $\begin{array}{l}\% \text { Citing problem(s) due to } \\
\text { circumcision }\end{array}$ & 22 & 22 & 63 & 54 \\
\hline $\begin{array}{l}\text { Person(s) who made decision to } \\
\text { circumcise }\end{array}$ & & & & \\
\hline - Mother & 80 & 87 & 56 & 68 \\
\hline - Father & 47 & 74 & 19 & 14 \\
\hline - Respondent & 4 & 5 & 4 & 8 \\
\hline - Grandfather & 1 & 5 & 21 & 21 \\
\hline - Grandmother & 3 & 1 & 1 & 1 \\
\hline - Uncle & 5 & 2 & 5 & 3 \\
\hline $\begin{array}{l}\text { - Aunt } \\
\text { - Don't know }\end{array}$ & NA & NA & 9 & 5 \\
\hline $\begin{array}{l}\text { At time of cutting, \% stating they } \\
\text { were opposed to being cut }\end{array}$ & 26 & 25 & 31 & $21^{* *}$ \\
\hline
\end{tabular}

$N B$ : * denotes $p$-value $<0.05, * *$ denotes $p$-value of $<0.01$, and $* * *$ denotes $p$-value $<0.001$.

The majority of respondents were cut by traditional FGC practitioners, followed by traditional birth attendants (TBAs) in both Ethiopia and Kenya. (These are sometimes the same people but respondents in the survey named them differently). There were significant differences between Ethiopia and Kenya in relation to the place of circumcision and whether a girl was 
cut alone or in a group. In Ethiopia, the majority of circumcisions took place in the open bush, while in Kenya they took place in the girl's home. Significantly higher proportions of circumcisions occurred in groups in Ethiopia than Kenya. In both Ethiopia and Kenya, the majority of the female respondents were cut using their own razor blade, although a high proportion of women in Ethiopia reported being cut using the traditional cutting blade for circumcision. Parents, especially mothers, were key decision makers regarding their daughter's circumcision although in Kenya, high proportions of respondents also mentioned grandparents. One in four respondents in both countries reported that they were not in favour of being cut at the time of their circumcision.

\section{Exposure to Intervention Messages and Activities}

\section{Exposure to Anti-FGC Messages}

To gauge exposure to FGC abandonment messages prior to and during the intervention, respondents were asked at baseline and endline if they had heard any anti-FGC messages, and if so, which messages they could recall, as well as the source of information. The intervention had the effect of significantly increasing the proportion of respondents exposed to anti-FGC messages in the intervention sites in both Ethiopia and Kenya, although this increase was much higher in Ethiopia than in Kenya (see Figure 2.1). The difference between the intervention and control sites in exposure to anti-FGC messages, during the baseline survey in Ethiopia, was not significant. However, this difference was significant at endline. The proportion of respondents exposed to anti-FGC messages had significantly increased in the intervention site. In Kenya, the difference between the intervention and the comparison sites was significant both at baseline and endline surveys.

\section{FIGURE 2.1 Percentage of respondents exposed to anti-FGC messages}

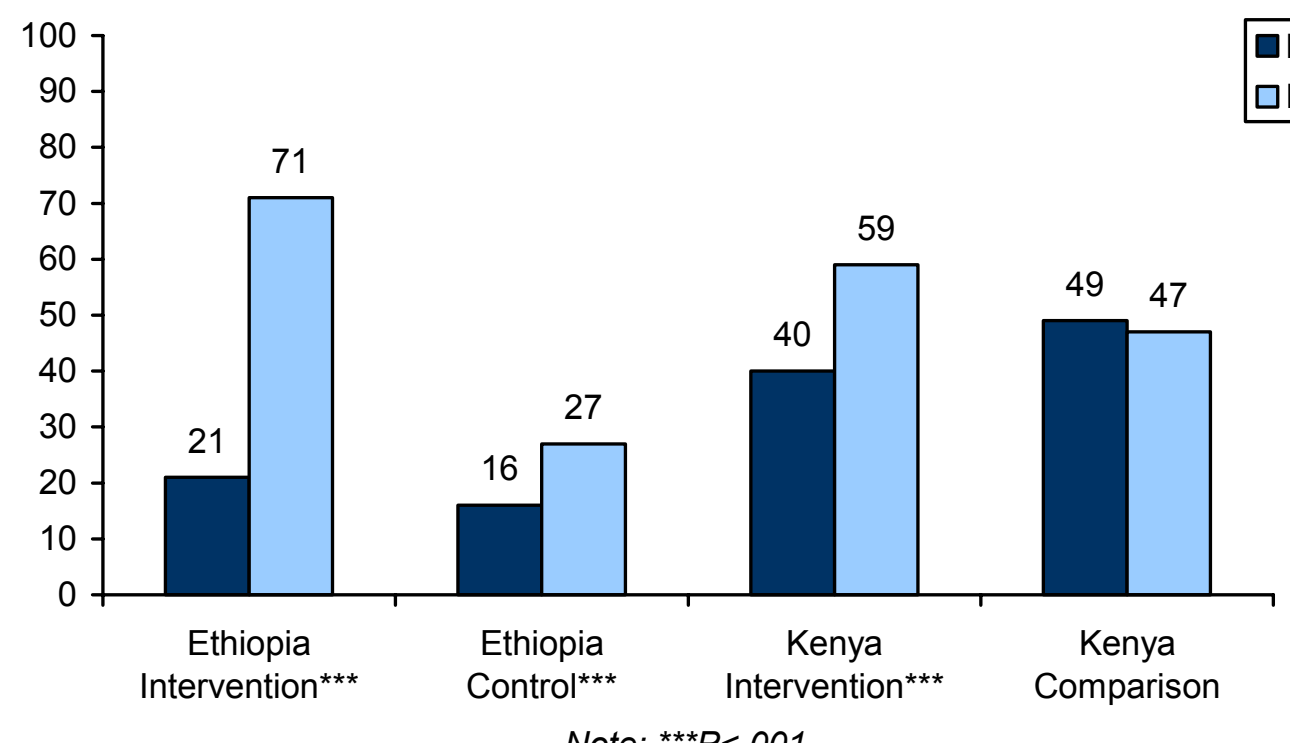

Note: ${ }^{* * *} P<.001$

In Ethiopia, women (21\%) from both the intervention and control sites were significantly ( $\mathrm{p}<$. $05)$ more likely to have been exposed than males (16\%) at baseline. At the endline survey, the gender difference ( $46 \%$ females, $52 \%$ males) was not significant. In Kenya, men (52\% and $59 \%$ ) were significantly ( $\mathrm{p}<.001)$ more likely than women $(36 \%$ and $48 \%)$ to have been exposed to anti-FGC messages during the baseline and endline survey respectively in both the intervention and comparison sites 
As Table 2.4 indicates, there were also significant age differences in exposure to anti-FGC messages in Ethiopia and Kenya at the baseline and endline surveys. In Kenya, the younger age groups were more likely to have been exposed to anti-FGC messages than older age groups at both the baseline and endline surveys in the intervention and comparison sites. However, in Ethiopia, no differential exposure by age was seen at all.

TABLE 2.4 Exposure to educational messages by age in Ethiopia and Kenya

\begin{tabular}{|c|c|c|c|c|}
\hline \multirow[b]{2}{*}{ Ethiopia } & \multicolumn{2}{|c|}{ Baseline } & \multicolumn{2}{|c|}{ Endline } \\
\hline & Intervention & Control & Intervention & Control \\
\hline $8-14$ years & 10 & 15 & 59 & 22 \\
\hline $15-24$ & 24 & 13 & 70 & 25 \\
\hline $25-34$ & 28 & 24 & 79 & 43 \\
\hline $35-44$ & 31 & 14 & 61 & 22 \\
\hline $45+$ & 14 & 18 & 81 & 18 \\
\hline P Value & .010 & .468 & .013 & .006 \\
\hline Kenya & Intervention & Comparison & Intervention & Comparison \\
\hline $15-24$ years & 46 & 53 & 61 & 55 \\
\hline $25-34$ & 42 & 59 & 69 & 49 \\
\hline $35-44$ & 34 & 43 & 60 & 43 \\
\hline $45+$ & 32 & 30 & 49 & 32 \\
\hline P Value & .006 & .000 & .003 & .000 \\
\hline
\end{tabular}

At the endline survey, respondents who reported that they had been exposed to anti-FGC messages in the past two years were asked to state what they did after receiving the messages. In Kenya and Ethiopia, around one-third of respondents said that hearing the anti-FGC messages led them to take some action (or change in intended action). Men were more likely than women to take some kind of action.

In Ethiopia, there was a significant difference $(p<.001)$ between the intervention and control sites in responses to this question. Of the 71 percent intervention and 27 percent control respondents who reported exposure to anti-FGC messages at the endline, 61 percent of intervention compared to 27 percent control site respondents said they did nothing; 23 percent of intervention site respondents, compared to 20 percent control site respondents, said they decided not to cut their daughters in the future. A higher proportion of control site (17\%) than intervention site (1\%) respondents decided to teach others about FGC and not to cut their daughters. Significantly more women (78\%) than men (42\%) said that they did nothing. However, more men than women said that they decided not to cut their daughters ( $31 \%$ versus 
$13 \%)$, to use the "sunna" type of cut instead of infibulation ${ }^{8}(12 \%$ versus $6 \%)$ and to teach others and not cut their daughters (10\% versus $1 \%)$.

In Kenya, the majority (68\%) of respondents both from the intervention $(70 \%)$ and comparison (66\%) sites said they did nothing. Nineteen percent said they gave advice to their friends, neighbors, and relatives regarding FGC abandonment; 11 percent decided not to cut their daughters in the future; and 2 percent decided to choose the "sunna" type instead of infibulation. The difference between the intervention and comparison sites was not significant. However, women $(75 \%)$ were significantly $(\mathrm{p}<.001)$ more likely to report that they did nothing compared to men (62\%). Men $(25 \%)$ were more likely to report that they gave advice to their friends, neighbors and relatives compared to women (13\%).

\section{Types of Messages}

During the endline survey, Kenyan respondents who said that they had heard of anti-FGC messages were asked to cite the different messages they had heard. ${ }^{9}$ More than half of the respondents mentioned the message that the pharoanic (infibulation) type of FGC cut is harmful to health. ${ }^{10}$ A comparison of the intervention and comparison site responses indicated that women and men from the intervention group were most likely to recall this message (64\%). Two-thirds of the male and female respondents from the comparison site mentioned medical complications. Slightly more men than women mentioned these two messages while more women than men mentioned messages that FGC is against religion, is a punishment against the girl and should be discouraged, and that it could cause death. It is important to note that the intervention sought to present FGC as a women's and girls' human rights issue, and as a practice that had not only health, but also psychosexual and social consequences, yet virtually no respondents $(1 \%)$ recalled the message that FGC violates the human rights of girls.

\footnotetext{
${ }^{8}$ While people are reporting a shift in the practice of FGC from the most severe form of infibulation to a less severe form of "sunna" or clitoridectomy, there is no empirical evidence that an actual change in the norm of type of cutting has occurred and if it has occurred, whether the new form resembles clitoridectomy or a more severe form of cutting.

${ }^{9}$ This set of questions was asked in Ethiopia but the data were not available in a usable format.

${ }^{10}$ Note that the project position was to end the practice of FGC, not just the severe form of infibulation practiced in the study sites.
} 
TABLE 2.5 Recall of type of messages exposed to in Kenya at endline

\begin{tabular}{|l||c|c||c|c|c||}
\hline & \multicolumn{2}{|c|}{ Intervention (n=428) } & \multicolumn{2}{c||}{ Comparison (n=338) } & Total (n=766) \\
\hline & $\begin{array}{c}\text { Females } \\
(\mathbf{n}=\mathbf{1 9 3})\end{array}$ & $\begin{array}{c}\text { Males } \\
(\mathbf{n}=\mathbf{2 3 5})\end{array}$ & $\begin{array}{c}\text { Females } \\
(\mathbf{n}=\mathbf{1 5 0})\end{array}$ & $\begin{array}{c}\text { Males } \\
(\mathbf{n = 1 8 8})\end{array}$ & \\
\hline $\begin{array}{l}\text { Pharaonic type harmful } \\
\text { to health }\end{array}$ & 60 & 67 & 45 & 37 & 53 \\
\hline Medical complications & 22 & 42 & 65 & 61 & 46 \\
\hline Against religion & 22 & 15 & 32 & 30 & 23 \\
\hline $\begin{array}{l}\text { Punishment to girls and } \\
\text { should be discouraged }\end{array}$ & 26 & 17 & 13 & 14 & 18 \\
\hline FGC can cause death & 20 & 7 & 19 & 11 & 14 \\
\hline A bad tradition & 2 & 0.4 & 5 & 3 & 2 \\
\hline $\begin{array}{l}\text { Violates rights of } \\
\text { girls/women }\end{array}$ & 1 & 0.4 & 1 & 1 & 1 \\
\hline
\end{tabular}

\section{Sources of Anti-FGC Messages}

During the endline survey, respondents who reported that they had heard anti-FGC messages in the past two years were asked to name the sources of their information and the places where messages were heard. CARE and partner agency staff were mentioned by the highest proportion of respondents in both Ethiopia and Kenya. It is important to note that community health workers, community development workers, and reproductive health monitors/extension supervisors are CARE and/or NCCK staff or refugee volunteers who provide FGC information and other outreach activities at the community level. In addition, CARE/NCCK used participatory educational theatre (PET) and seminars/workshops as strategies to encourage dialogue and debate on FGC and educate community members in the two study sites in Kenya and in the intervention site in Ethiopia. Therefore, significant proportions of respondents mentioning these sources were exposed to CARE and NCCK FGC intervention activities.

In Kenya, radio was ranked as the second highest source of anti-FGC messages, especially in the comparison site. In Ethiopia, religious leaders were the second highest source of antiFGC messages. It is important to note that although advocacy through religious leaders was one of the key strategies used in the intervention sites in Ethiopia and Kenya (though in Kenya the work with religious leaders was never fully realized), an almost equal proportion of respondents from the intervention and control/comparison sites (40\% versus 35\% in Ethiopia and $23 \%$ versus $30 \%$ in Kenya), cited religious leaders as their source for anti-FGC messages, which raises questions about the possibility of contamination of the intervention strategies in the control/comparison sites and the weakness of the intervention.

In Ethiopia, it is also important to note the possibility of significant diffusion of FGC messages from CARE into the control site. This "contamination" of the control site in Ethiopia is partly attributable to the Afar migratory/semi-nomadic nature and their traditional communication system, Dagu. Although CARE did not have any activities in the control site in Ethiopia, a significant proportion (30\%) of respondents in the control site mentioned CARE as the source of their anti-FGC messages, and a quarter mentioned the Dagu system. Dagu is a highly developed traditional system of information management. It serves to transmit issues 
pertaining to conflicts, pastures, weather, health and markets by word of mouth. The system requires an Afar man to provide information on any new developments or information that they are aware of to other Afar men who they interact with, and to mention the source of that information. Therefore, when fellow Afar people meet they must exchange Dagu, for the Afar are required to pass on information and to proactively seek information. Children come of age in the use of Dagu at age 15. It is therefore as important a rite of passage as ritual circumcision is and the penalty for false information is very severe. During the dry season, the Afar migrate for long periods to areas with better pasture for their livestock. It is possible that people from different villages interact during this migration period. Respondents citing CARE as the source of information may have either interacted directly with CARE staff during this period, or received the information through the Dagu system.

The places where people received anti-FGC messages varied. Door-to-door campaigns, seminars/workshops, and the mosque were mentioned by more than a quarter of the respondents in Ethiopia and in Kenya. The market place was mentioned by a significant number of respondents in Kenya, particularly from the intervention site (34\%).

\section{Changes in Knowledge of Harmful Effects of FGC}

Respondents were asked if they knew of any health, psychosexual, or social problems associated with the practice of FGC. Knowledge of harmful effects was assessed by comparing the proportion of respondents who did not mention any harmful effect with the proportion of responses for health, psychosexual, and social effects separately. In addition, a knowledge score was created by adding all the correct responses mentioned and using this to calculate mean knowledge scores.

Figure 2.2 shows that knowledge of negative FGC effects increased significantly between the baseline and endline surveys in both Ethiopia and Kenya. The intervention sites in both Ethiopia $(-80.3 \%$ versus $-56.72 \%)$ and Kenya $(-79 \%$ versus $-62 \%)$ had significantly greater reduction in the proportion of people who did not know any negative FGC effect, and in the increase of mean knowledge scores from baseline to endline as compared to the control/comparison sites.

\section{FIGURE 2.2 Percentage of respondents who did not know any negative FGC effects}

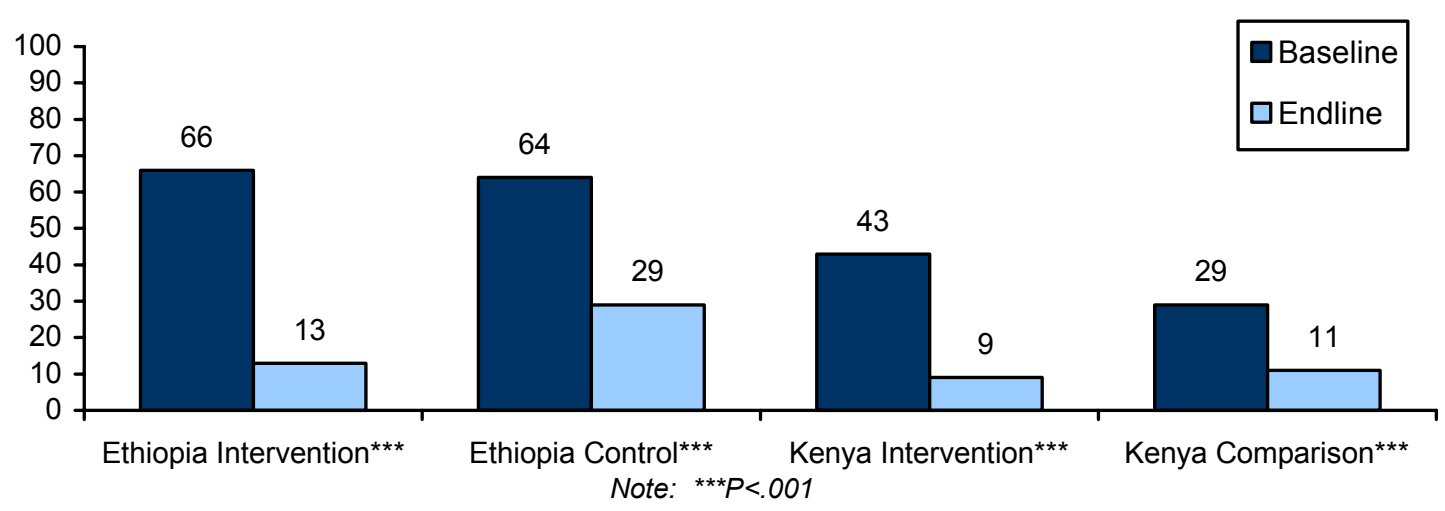

At baseline, knowledge of harmful health effects was much higher than knowledge of psychosexual and social effects both in Ethiopia and in Kenya. The strategy of focusing on increasing knowledge of harmful psychosexual and social effects paid off in Ethiopia and to a lesser extent in Kenya; social and psychosexual effects had the highest and second highest 
increase in mean knowledge score respectively. In the intervention site in Ethiopia, the proportion of respondents who mentioned at least one social and one psychosexual effect was higher than those who mentioned at least one health effect. However, in Kenya, the proportion of respondents who mentioned at least one health effect was higher than those who mentioned at least one psychosexual and one social effect in both intervention and comparison sites. This supports the earlier finding that respondents in Kenya could mainly recall only health messages.

\section{Knowledge of Harmful Health Effects}

In both Ethiopia and Kenya, the intervention had a significant effect in increasing knowledge of negative health effects. There were 12 possible correct responses for the negative health effects of FGC (Box 1). As Figure 2.3 indicates, in Ethiopia, knowledge of negative health effects was very low in both the intervention and control sites at baseline. By the endline survey, the intervention site population, as compared to the control site, had a significantly greater magnitude of change between baseline and endline in mean knowledge score (See Table 2.6) and in percentage of respondents $(+533 \%$ compared to $+75 \%)$ who mentioned more than two health effects.

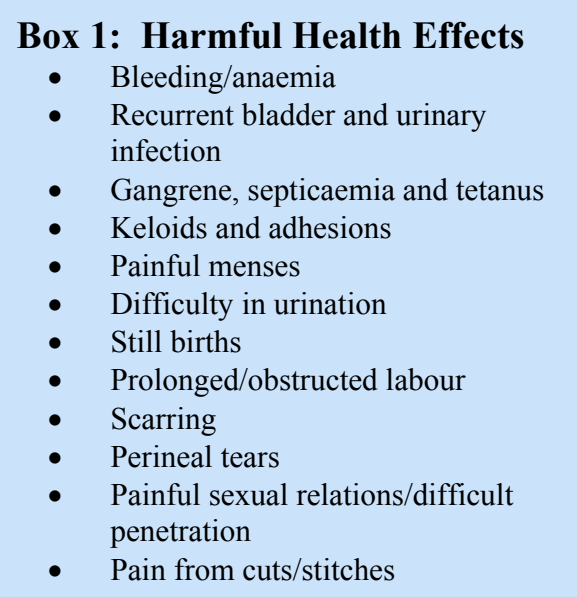

In Kenya, as shown on Figure 2.3, knowledge of negative health effects was higher compared to Ethiopia. This proportion reduced significantly over time in both the intervention and comparison sites. However, the reduction in proportion of respondents who did not mention even one negative health effect was significantly higher in the intervention (-67\%) compared to the comparison $(-52 \%)$ site. The comparison site had significantly higher mean knowledge score at baseline and although this score was still significantly higher in the comparison site at endline, the intervention site had a higher magnitude of change in mean knowledge score between baseline and endline (See Table 2.6).

\section{FIGURE 2.3 Percentage of respondents who did not know any negative health FGC} effects

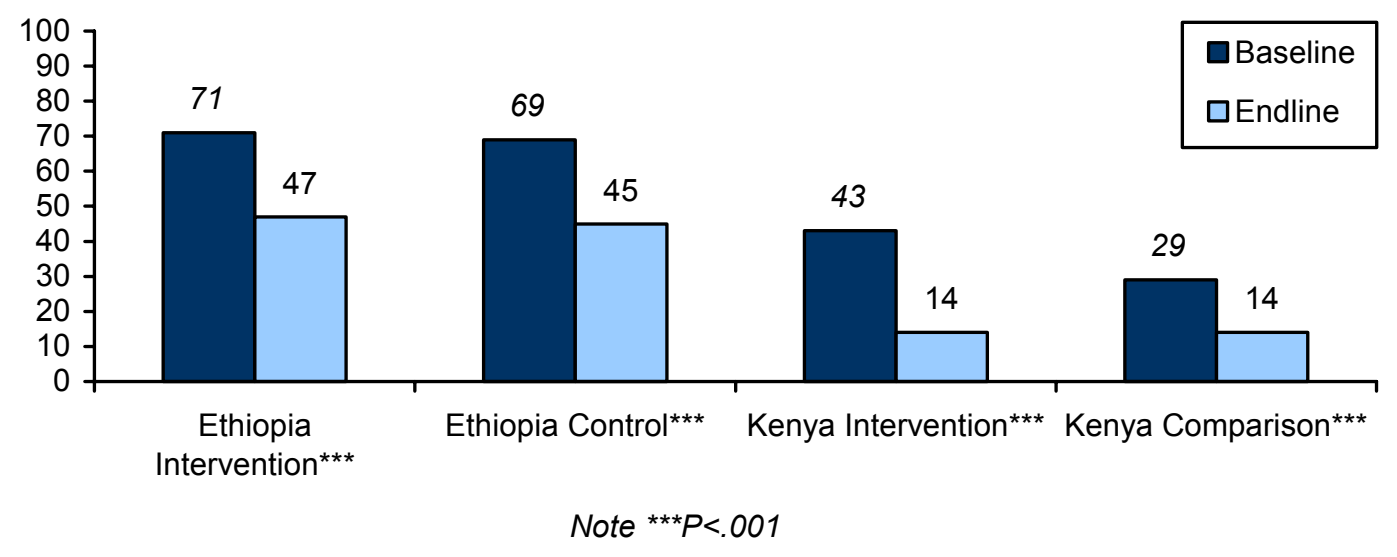

TABLE 2.6 Comparison of changes in mean knowledge scores of negative FGC effects between intervention and control/comparison sites

\begin{tabular}{|l|l|l|l|c|}
\hline & \multicolumn{2}{|c|}{ Intervention Site } & \multicolumn{2}{c|}{ Control/Comparison Site } \\
\hline & Baseline & Endline & Baseline & Endline \\
\hline
\end{tabular}




\begin{tabular}{|c|c|c|c|c|}
\hline \multicolumn{5}{|l|}{ Ethiopia } \\
\hline Health effects & 0.52 & $3.38^{* * *}$ & 0.79 & $1.39^{* * *}$ \\
\hline Psychosexual effects & 0.71 & $1.09^{\star \star *}$ & 0.11 & $0.52^{* * *}$ \\
\hline Social effects & 0.12 & $1.18^{\star * *}$ & 0.31 & $0.56^{* * *}$ \\
\hline All negative effects & 0.80 & $5.65^{\star * *}$ & 1.03 & $2.47^{* * *}$ \\
\hline \multicolumn{5}{|l|}{ Kenya } \\
\hline Health effects & 1.83 & $3.04^{* * *}$ & 2.14 & $3.28^{* * *}$ \\
\hline Psychosexual effects & 0.20 & $1.09^{* * *}$ & 0.20 & $0.93^{* * *}$ \\
\hline Social effects & 0.18 & $0.87^{\star * *}$ & 0.12 & $0.95^{* * *}$ \\
\hline All negative effects & 2.21 & $5.00^{\star * *}$ & 2.47 & $5.17^{* * *}$ \\
\hline
\end{tabular}

$N B$ : *** denotes $P$-value $<0.001$

\section{Knowledge of Harmful Psychosexual Effects}

The intervention significantly increased the respondents' knowledge of negative FGC psychosexual effects in both Ethiopia and Kenya. There were three possible negative psychosexual effects of FGC (Box 2). Knowledge of negative psychosexual effects was lower overall when compared to knowledge of negative health effects in Ethiopia and Kenya both in the intervention and control/comparison sites.

In Ethiopia, the intervention site (-59\%)

Box 2: Negative psychosocial and social effects

Negative Psychosexual Effects

- Fear of sexual penetration

- Psychological trauma and depression

- Lack of / prevents sexual satisfaction

Negative Social Effects

- Marital conflicts

- Lowering dignity of women

- Limits girls' education

- Encourages early marriage

had a significantly greater reduction in the proportion of respondents who did not know of any psychosexual effect, compared to the control site (-24\%). In addition, the magnitude of change between the baseline and endline survey in the proportion of respondents who mentioned more than two negative effects and the mean knowledge score were significantly higher in the intervention than the control site. As Figure 2.4 indicates, the trends in Kenya were similar to Ethiopia; although there were significant increases in knowledge of negative psychosexual effects in both sites, the magnitude of change was significantly greater in the intervention (-60\%), compared to the comparison (-51\%) site.

\section{FIGURE 2.4 Percentage of respondents who did not know any negative psychosexual} FGC effects

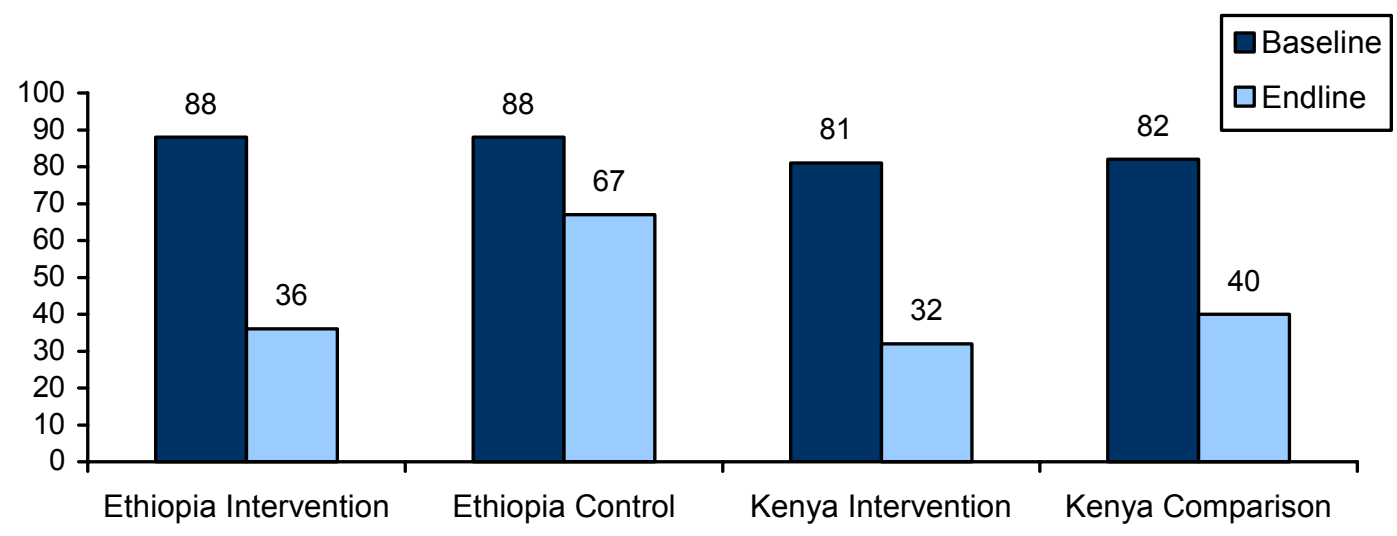

Note: $P<.001$ 


\section{Knowledge of Harmful Social Effects}

The intervention had the effect of significantly increasing respondents' knowledge of negative social effects of FGC in both Ethiopia and Kenya. However, for Kenya, the comparison site had a significantly greater magnitude of change in knowledge from baseline to endline, as compared to the intervention site.

As with psychosocial effects, knowledge of negative social effects was also much lower than knowledge of health effects in both Ethiopia and Kenya. More than four-fifths of respondents did not mention any negative social effect at baseline. By the time of the endline survey, knowledge of negative social effects had increased significantly. In Ethiopia, the proportion of respondents who did not mention any social effect had reduced to about one-third in the intervention site, and to less than two-thirds in the control site. In Kenya, this proportion had reduced to two-fifths in both the intervention and comparison sites.

\section{Effect of Socio-demographic Characteristics on Knowledge of Harmful Effects of FGC}

In both Ethiopia and Kenya, men had significantly higher mean knowledge scores than women during the baseline survey. In Ethiopia, men still had significantly higher mean knowledge scores than women at the endline survey, but the magnitude of change between baseline and endline was higher among women (413\% compared to 303\%) when the difference between baseline and endline is compared to baseline. As Table 2.7 indicates, at endline in Kenya, women (157\%) not only had a significantly higher magnitude of change than men (84\%), but they also had significantly higher mean knowledge scores for all negative effects.

There were no significant differences in mean knowledge scores between the ever married and never married respondents, with the exception of Ethiopia during the endline survey (See Table 2.7). Baseline marital status data was not available for Ethiopia.

As shown in Table 2.7, both baseline and endline data indicate that respondents who had primary and above level of education had significantly higher mean knowledge scores compared to those with no formal schooling. In both educational groups in Ethiopia and Kenya, mean knowledge scores increased significantly between baseline and endline.

In Ethiopia, the older age groups (45+ years and 35-44 years) had larger increases in mean knowledge scores compared to the younger groups. In Kenya, the younger age groups (15-24 years and 25-34 years) had higher mean knowledge scores compared to the older age groups at both the baseline and endline surveys.

TABLE 2.7 Comparison of differences in mean knowledge scores of all negative FGC effects by socio-demographic characteristics

\begin{tabular}{|c|l|l|l|l|}
\hline & \multicolumn{2}{|c|}{ Ethiopia } & \multicolumn{2}{c|}{ Kenya } \\
\hline & Baseline & Endline & Baseline & Endline \\
\hline Gender & 0.68 & 3.49 & 2.14 & 5.49 \\
\hline Female & $1.16^{* * *}$ & $4.67^{* * *}$ & $2.55^{* * *}$ & $4.70^{* * *}$ \\
\hline Male & N/A & 3.79 & 2.28 & 5.13 \\
\hline Marital Status & \multicolumn{5}{|l|}{} \\
\hline Ever Married &
\end{tabular}




\begin{tabular}{|l|l|l|l|l|}
\hline Never Married & N/A & $4.43^{*}$ & 2.44 & 5.02 \\
\hline Education Level & \multicolumn{5}{|l|}{} \\
\hline No formal schooling & 0.86 & 3.67 & 2.09 & 4.73 \\
\hline Primary and above & $1.36^{* *}$ & $5.64^{* * *}$ & $2.72^{* * *}$ & $5.77^{* * *}$ \\
\hline Age & 0.36 & 3.69 & N/A & N/A \\
\hline $8-14$ & 1.25 & 4.51 & 2.43 & 5.23 \\
\hline $15-24$ & 1.19 & 3.97 & 2.75 & 5.47 \\
\hline $25-34$ & 0.98 & 3.53 & 2.25 & 4.29 \\
\hline $35-44$ & $0.83^{* * *}$ & 4.16 & $1.86^{* * *}$ & $4.34^{* * *}$ \\
\hline $45+$ & $* 20.01$ and $* * *<0.001$ &
\end{tabular}

N/A denotes data not available or not applicable

A linear regression analysis was undertaken to assess the impact of the intervention in increasing knowledge of harmful FGC effects, while controlling for the socio-demographic differences found to be significantly associated with knowledge of harmful effects during bivariate analysis. In addition, exposure to anti-FGC messages was included in the model, because bivariate analysis indicated that respondents who had ever been exposed to anti-FGC messages were significantly more likely to have higher mean knowledge scores than those who had not been exposed to anti-FGC messages.

The linear regression model (See Annex 2 Table 1) indicates that in both Ethiopia and Kenya, there was an observed increase in knowledge between the baseline and endline. Differences in gender, education, and exposure to anti-FGC messages remain significantly associated with knowledge of harmful FGC effects. The intervention differences remain significant only in Ethiopia and age is not significantly associated with knowledge of harmful FGC effects in either Ethiopia or Kenya.

\section{Changes in attitudes and beliefs associated with FGC}

Prevailing attitudes and beliefs around the practice of FGC help to drive the continuation of the practice; therefore, they were addressed in FGC abandonment interventions as points for discussion and debate. A wide range of attitudes and beliefs were surveyed, including attitudes about whether FGC should continue within the community, awareness of human rights, whether the practice compromised any human rights, and looking more broadly, attitudes and beliefs on how equal relations between the sexes should be within the couple, household, and society.

\section{Beliefs related to fulfillment of human rights}

A strategy of the intervention was to present FGC not only as a health issue, but also equally as a human rights issue. In both Ethiopia and Kenya, the interventions resulted in very large increases in the belief that the rights of women and of girls were compromised by the practice of FGC. ${ }^{11}$ While the proportions of respondents holding this belief at baseline in Ethiopia is significantly less than in Kenya, by the endline survey, the gains in Ethiopia were so significant that, in many cases, they matched the endline proportions of Kenyan respondents (See Figure 2.5 and Figure 2.6).

\footnotetext{
${ }^{11}$ Recall that there were direct messages related to human rights and FGC in Kenya during the intervention period. In Ethiopia, there were no direct educational messages speaking to human rights, just actions that would promote gender equity.
} 
At baseline, Ethiopian respondents showed significant differences in opinion between intervention and control groups. In particular, significantly higher proportions of men in the control site believed that FGC compromised the human rights of women and girls than from the intervention site. By endline, the change in beliefs among intervention men and women had increased to the extent that the intervention site respondents had significantly higher proportions ( $425 \%$ and $600 \%$ respectively) than the control ( $90 \%$ and $70 \%$ respectively) site.

In Kenya at baseline, in both the intervention and comparison groups, about one in four respondents already held the belief that the human rights of women were compromised by the practice of FGC. By the endline survey, the proportion of people who believed that FGC compromised women's rights had increased in both groups, but significant differences were in an unexpected direction: the comparison group's beliefs increased more than the intervention group's ( $48 \%$ increase and $24 \%$ increase respectively) for all respondents (men and women), as well as for women respondents alone. A similar finding is seen when respondents were asked whether FGC compromised the rights of girls; increases in this belief occurred in all groups by endline, yet the comparison group's beliefs ( $56 \%$ increase) changed more than the intervention group's beliefs ( $43 \%$ increase).

\section{FIGURE 2.5 Percentage of respondents who stated that FGC violates women's rights}

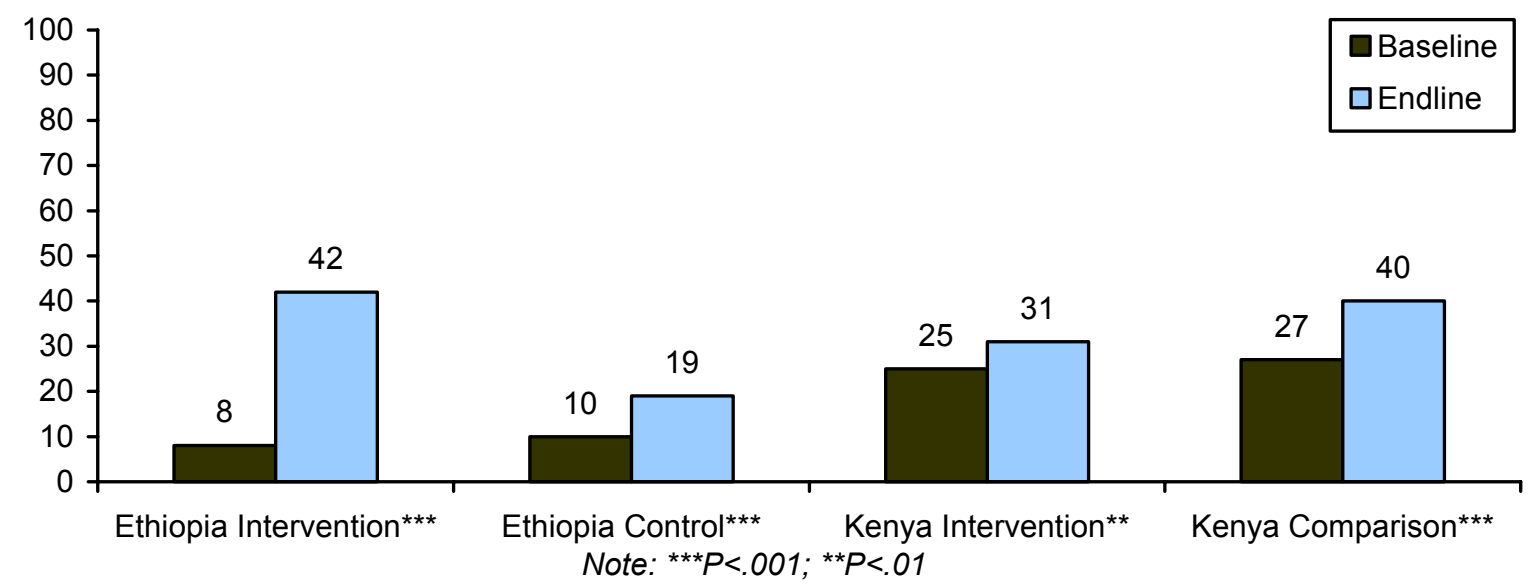

FIGURE 2.6 Percentage of respondents stating that FGC violates girls' rights

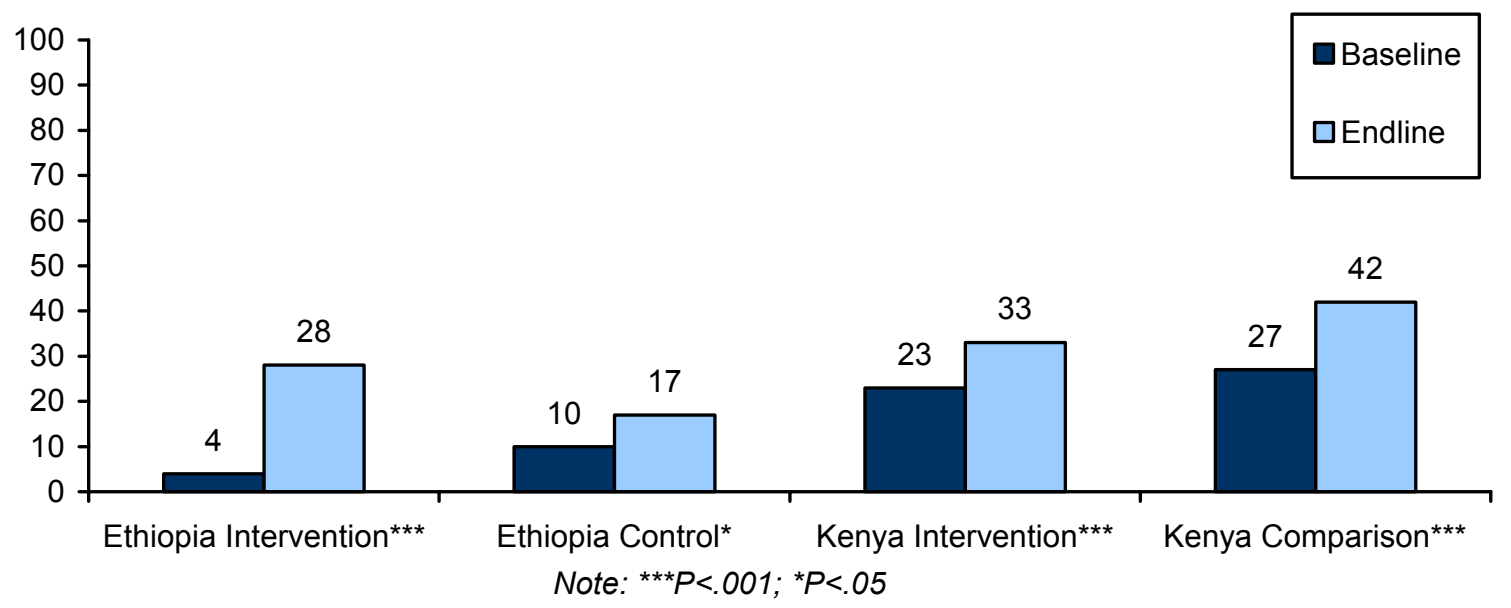




\section{Effects of socio-demographic characteristics on the beliefs that FGC is a human rights issue}

Gender, education, exposure to anti-FGC messages, and future intentions regarding cutting daughters were significantly associated with the attitude that FGC violates women's and girls' rights. Both in Ethiopia and Kenya, during baseline and endline surveys, male respondents and respondents who had primary and above levels of education, were exposed to anti-FGC messages, and expressed the view that they did not intend to cut their daughters in the future were significantly more likely to view FGC as a human rights violation issue. The magnitude of increase in proportions expressing the view that FGC violates the rights of women and girls was higher among men than women, except for the comparison site in Kenya, where women had a higher magnitude of change than men. Marital status and age were significantly associated with women's and girls' human rights attitudes in Kenya, but not in Ethiopia. Never married and younger respondents were more likely than married and older respondents, respectively, to express the view that FGC violates the rights of women and girls.

The results of multivariate logistic regression analysis indicate (See Annex 2 Table A2.2, and A2.3) that both in Ethiopia and Kenya, gender, education, and exposure to anti-FGC information remain significant factors associated with both the attitude that FGC contravenes the rights of women and the attitude that FGC violates girls' rights. The significant site difference observed in Ethiopia is not significant in the multivariate model for the women's human rights attitude, but was significant for girls' rights. Age remained a significant factor in Kenya, but not in Ethiopia.

\section{Related issues of gender equality}

The survey included questions to measure attitudes and beliefs associated with larger issues of gender equality. ${ }^{12}$ It was hypothesized that changes in women's self-esteem and/or men's support of women's empowerment could contribute in part to a change in attitude towards the practice of FGC, if observed at endline.

During the baseline and endline surveys, respondents were asked whether they agreed or disagreed with nine statements. The statements sought to reveal attitudes towards gender equality in intimate relationships and in various domains of decision-making within the couple and the larger community. These statements would also help reveal beliefs in the rights of women and girls to lead lives to their fullest potential, on par with men and boys. Table 2.8 presents the statements and responses and provides an analysis of the mean scores of all responses concerning gender equality (the magnitude of change in these attitudes could not be calculated in Ethiopia because baseline data was not available).

\footnotetext{
${ }^{12}$ Gender equality refers to situations where men and women are permitted equal enjoyment of human rights, socially valued goods, opportunities, resources, and the benefits from development results. Gender equity is the process of being fair to women and men. To ensure fairness, measures must be available to compensate for historical and social disadvantages that prevent women and men from operating on a level playing field. Gender equity strategies are used to eventually attain equality. Equity is the means; equality is the result (definitions of the USAID Inter-Agency Working Group on Gender). While the CARE project employed gender equity strategies, the statements in this section, and subsequent discussion of changes in attitudes, focused on the results or gender equality.
} 
TABLE 2.8 Proportion of respondents agreeing with statements on equality between sexes, and mean score of "positive" gender equality responses

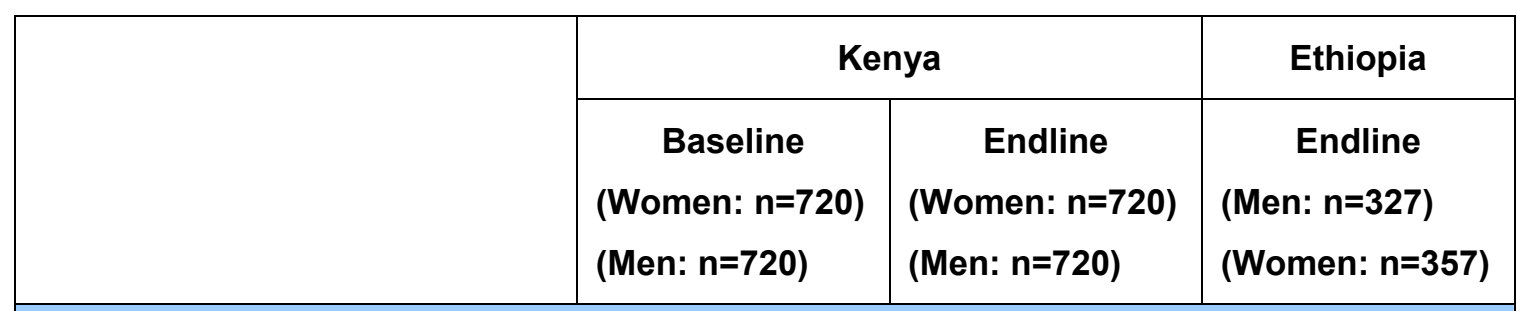

1: Your partner has more say than you do about important decisions that affect both of you.

\begin{tabular}{|l|l|c|c|c|}
\hline Agree & Men & 47 & $38^{* * *}$ & 32 \\
\cline { 2 - 5 } & Women & 54 & $50^{*}$ & $68^{* * *}$ \\
\hline \multirow{2}{*}{ Disagree } & Men & 44 & 57 & 64 \\
\cline { 2 - 5 } & Women & 35 & 41 & 23 \\
\hline \multirow{2}{*}{ No opinion } & Men & 9 & 6 & 4 \\
\cline { 2 - 5 } & Women & 11 & 9 & 10 \\
\hline
\end{tabular}

2: When your partner and you disagree, you get your way most of the time.

\begin{tabular}{|l|l|c|c|c|}
\hline \multirow{2}{*}{ Agree } & Men & 32 & $49^{* * *}$ & 73 \\
\cline { 2 - 5 } & Women & 36 & $29^{* * *}$ & $45^{* * *}$ \\
\hline \multirow{2}{*}{ Disagree } & Men & 60 & 40 & 24 \\
\cline { 2 - 5 } & Women & 53 & 53 & 46 \\
\hline \multirow{2}{*}{ No opinion } & Men & 8 & 11 & 3 \\
\cline { 2 - 5 } & Women & 11 & 19 & 9 \\
\hline
\end{tabular}

3: Women should have equal opportunities as men to hold senior political and social positions in the community.

\begin{tabular}{|l|l|c|c|c|}
\hline \multirow{2}{*}{ Agree } & Men & 43 & $44^{* * *}$ & 63 \\
\cline { 2 - 5 } & Women & 59 & $51^{* * *}$ & $50^{* * *}$ \\
\hline \multirow{2}{*}{ Disagree } & Men & 49 & 53 & 35 \\
\cline { 2 - 5 } & Women & 35 & 38 & 34 \\
\hline \multirow{2}{*}{ No opinion } & Men & 8 & 3 & 2 \\
\cline { 2 - 5 } & Women & 6 & 11 & 17 \\
\hline
\end{tabular}

\begin{tabular}{|l|l|l|}
\hline & Kenya & Ethiopia \\
\hline
\end{tabular}




\begin{tabular}{|c|c|c|c|c|}
\hline & & $\begin{array}{l}\text { Baseline } \\
\text { (Women: } n=720 \text { ) } \\
\text { (Men: } n=720 \text { ) }\end{array}$ & \begin{tabular}{l}
\multicolumn{1}{c}{ Endline } \\
(Women: $n=720)$ \\
(Men: $n=720)$
\end{tabular} & \begin{tabular}{l}
\multicolumn{1}{c}{ Endline } \\
(Men: $n=327$ ) \\
(Women: $n=357$ )
\end{tabular} \\
\hline \multicolumn{5}{|c|}{$\begin{array}{l}\text { 4: A girls should have equal rights as a boy child to express her opinion and participate in } \\
\text { decisions concerning her future. }\end{array}$} \\
\hline \multirow[t]{2}{*}{ Agree } & Men & 64 & 65 & 64 \\
\hline & Women & 64 & $70^{* *}$ & $59^{* * *}$ \\
\hline \multirow[t]{2}{*}{ Disagree } & Men & 32 & 32 & 34 \\
\hline & Women & 32 & 24 & 30 \\
\hline \multirow[t]{2}{*}{ No opinion } & Men & 4 & 3 & 3 \\
\hline & Women & 4 & 6 & 11 \\
\hline \multicolumn{5}{|c|}{ 5: It is appropriate for a woman to express feelings of sexual satisfaction. } \\
\hline \multirow[t]{2}{*}{ Agree } & Men & 51 & $59^{\star \star *}$ & 29 \\
\hline & Women & 36 & $17^{\star * \star}$ & $14^{* \star *}$ \\
\hline \multirow[t]{2}{*}{ Disagree } & Men & 30 & 30 & 60 \\
\hline & Women & 42 & 52 & 47 \\
\hline \multirow[t]{2}{*}{ No opinion } & Men & 19 & 12 & 11 \\
\hline & Women & 22 & 31 & 39 \\
\hline \multicolumn{5}{|c|}{$\begin{array}{l}\text { 6: When money is scarce and the family cannot afford to send all children to school, boys } \\
\text { should be sent before girls. }\end{array}$} \\
\hline \multirow[t]{2}{*}{ Agree } & Men & 43 & $30^{* \star *}$ & 65 \\
\hline & Women & 46 & 45 & $53^{\star \star \star *}$ \\
\hline \multirow[t]{2}{*}{ Disagree } & Men & 53 & 68 & 30 \\
\hline & Women & 51 & 50 & 33 \\
\hline \multirow[t]{2}{*}{ No opinion } & Men & 4 & 3 & 5 \\
\hline & Women & 4 & 6 & 15 \\
\hline
\end{tabular}

\begin{tabular}{|c|c|c|c|}
\hline & \multicolumn{2}{|c|}{ Kenya } & Ethiopia \\
\hline & \begin{tabular}{l}
\multicolumn{1}{c}{ Baseline } \\
(Women: $n=720)$ \\
(Men: $n=720)$
\end{tabular} & $\begin{array}{l}\text { Endline } \\
\text { (Women: } n=720 \text { ) } \\
\text { (Men: } n=720)\end{array}$ & $\begin{array}{l}\quad \text { Endline } \\
\text { (Men: } n=327 \text { ) } \\
\text { (Women: } n=357 \text { ) }\end{array}$ \\
\hline
\end{tabular}


7: Men have a right to sexual enjoyment every time they have sex.

\begin{tabular}{|l|l|c|c|c|}
\hline \multirow{2}{*}{ Agree } & Men & 76 & $87^{* * *}$ & 74 \\
\cline { 2 - 5 } & Women & 44 & 47 & $24^{* * *}$ \\
\hline \multirow{2}{*}{ Disagree } & Men & 12 & 12 & 14 \\
\cline { 2 - 5 } & Women & 26 & 22 & 23 \\
\hline \multirow{2}{*}{ No opinion } & Men & 12 & 1 & 13 \\
\cline { 2 - 5 } & Women & 29 & 31 & 53 \\
\hline
\end{tabular}

8: Women have a right to sexual enjoyment every time they have sex.

\begin{tabular}{|l|l|c|c|c|}
\hline \multirow{2}{*}{ Agree } & Men & 58 & $59^{* * *}$ & 55 \\
\cline { 2 - 5 } & Women & 39 & $20^{* * *}$ & $17^{* * *}$ \\
\hline \multirow{2}{*}{ Disagree } & Men & 26 & 34 & 31 \\
\cline { 2 - 5 } & Women & 42 & 52 & 31 \\
\hline \multirow{2}{*}{ No opinion } & Men & 17 & 7 & 14 \\
\cline { 2 - 5 } & Women & 19 & 29 & 53 \\
\hline
\end{tabular}

9: Men and women should have equal rights in all aspects of life.

\begin{tabular}{|c|c|c|c|c|}
\hline \multirow[t]{2}{*}{ Agree } & Men & 42 & 43 & 67 \\
\hline & Women & 66 & $28^{* * *}$ & $55^{* * *}$ \\
\hline \multirow[t]{2}{*}{ Disagree } & Men & 51 & 51 & 31 \\
\hline & Women & 27 & 61 & 32 \\
\hline \multirow[t]{2}{*}{ No opinion } & Men & 7 & 6 & 3 \\
\hline & Women & 8 & 11 & 13 \\
\hline \multirow{2}{*}{$\begin{array}{l}\text { Mean score of } \\
\text { positive gender } \\
\text { equality }\end{array}$} & Men & 3.88 & $4.25^{\star \star \star}$ & 3.72 \\
\hline & Women & 3.59 & $2.82^{* * *}$ & $2.47^{* * *}$ \\
\hline
\end{tabular}

$N B$ : * denotes $p$-value $<0.05, * *$ denotes $p$-value of $<0.01$, and $* * *$ denotes $p$-value $<0.001$. 
In Kenya, at both baseline and endline surveys, the differences between intervention and comparison groups for most of the gender equality indicators was significant, with the comparison site respondents tending to express more gender-equal opinions compared to the intervention site. Comparison site respondents had significantly higher mean scores in positive gender equality attitudes during both the baseline and endline surveys. Although the change in mean positive gender scores increased significantly in the intervention $(p<.05$; $\mathrm{t}=2.07)$ group, it decreased significantly in the comparison $(\mathrm{p}<.001 ; \mathrm{t}=5.81)$ group.

The statements given in Table 2.8 represent three situations where attitudes towards gender equality are assessed, e.g., in decision-making around family and child-raising issues (statements 1, 2, 4, and 6), in intimate relations within the couple (statements 5, 7, and 8), and in terms of societal roles ( 3 and 9). Viewed this way, the responses between baseline and endline surveys reveal shifts in Kenya, not necessarily in expected ways, in men and women's opinions in different domains between the endline and baseline survey periods.

Both in Kenya and Ethiopia, men, more than women, were more likely to be in agreement with statements in support of equality for women. Mean scores of positive gender equality responses were significantly higher for men than women at both at baseline (in Kenya) and endline. In Kenya, changes in responses to gender equity questions indicate that the intervention may have increased gender disparities. While the mean score of positive gender equality responses increased in men, it reduced significantly in women.

\section{Support for FGC abandonment in the community}

People were asked if in their view the practice of FGC should be abandoned in their community. As Figure 2.7 shows, there were significant changes in favour of abandoning the practice in Ethiopia (increasing by $145 \%$ in the intervention site compared to $67 \%$ in the control site), whereas in Kenya, there was no change in the intervention site, but the increase in the control site was significant.

\section{FIGURE 2.7 Proportions of respondents who supported FGC abandonment in Ethiopia and Kenya}

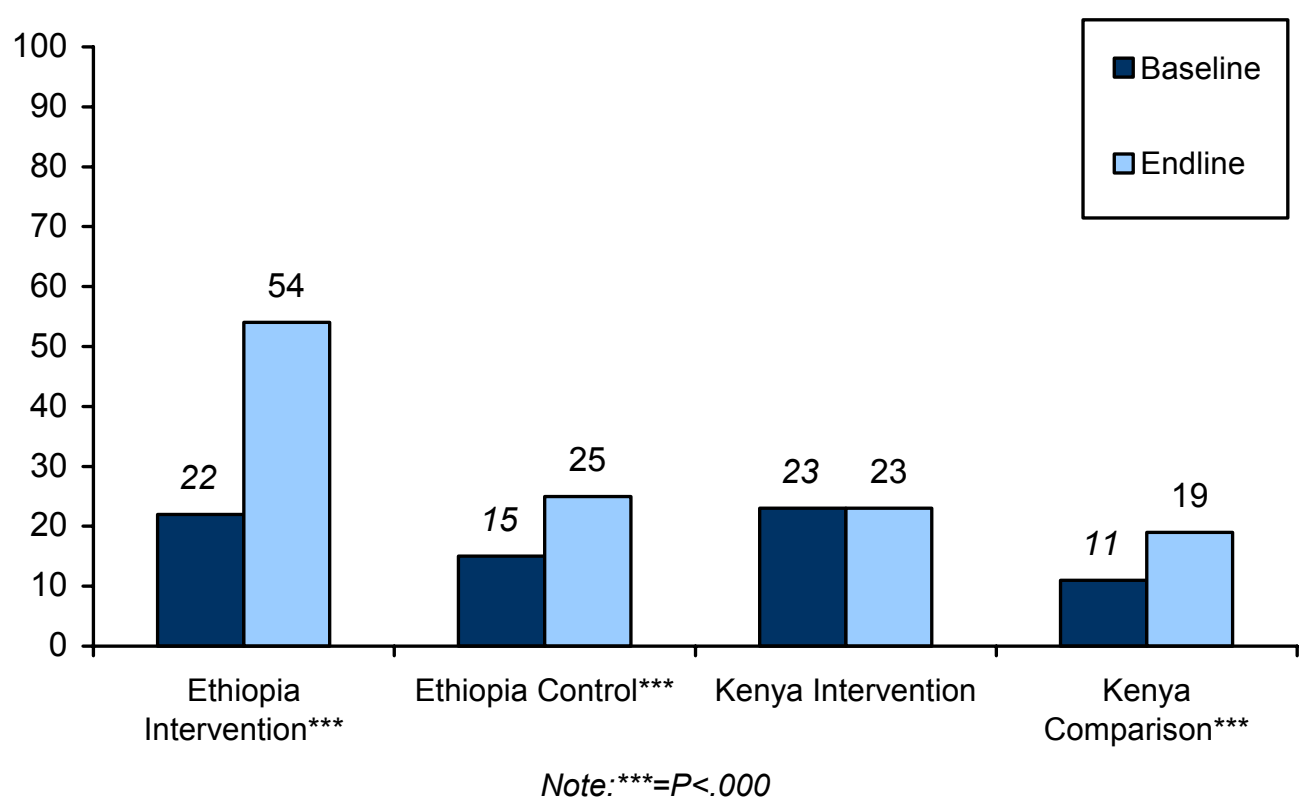


In Ethiopia at baseline, the differences between men and women in their support for FGC abandonment were not significant. However, during the endline survey, males (46\%) were significantly $(\mathrm{p}<.001)$ more likely to support FGC abandonment than females $(33 \%)$.

However, this overall gender difference is attributable mainly to the differences found in the intervention site, where males $(68 \%)$ were significantly $(\mathrm{p}<.001)$ more likely to support FGC abandonment than women (41\%).

Similarly, there are significant gender differences in support for FGC abandonment in Kenya. During the baseline survey, males $(23 \%)$ were significantly $(\mathrm{p}<.01)$ more likely to express the view that FGC should be abandoned than females (19\%). There were similar trends during the endline survey, where males $(28 \%)$ were significantly $(\mathrm{p}<.001)$ more likely than females $(13 \%)$ to express this view. These differences were significant in both intervention and comparison sites.

Marital status was not significantly associated with support for FGC abandonment in Kenya and Ethiopia. Although education, age, and exposure to anti-FGC messages were significantly associated with support for FGC abandonment in Ethiopia, these indicators were not significant in Kenya during both the baseline and endline surveys. Respondents who had primary and above level of education and those who had been exposed to anti-FGC messages were significantly more likely to support FGC abandonment than their counterparts, during both the baseline and endline surveys. The age correlation was not linear.

Results of a multiple regression analysis model that included these socio-demographic and exposure to anti-FGC messages indicators (See Annex 2, Table A2.4) revealed that the type of site and the time of survey remained significantly associated with support for FGC abandonment in Ethiopia and Kenya. The odds that respondents from the intervention sites would support FGC abandonment were 0.59 and 0.57 higher (Ethiopia and Kenya respectively) than in the control/comparison sites. Endline survey respondents were 1.6 and 1.2 times more likely than the baseline survey respondents to support FGC abandonment in Ethiopia and Kenya respectively. The gender differences remained significant in Kenya, but not in Ethiopia. Education, exposure to anti-FGC messages, and age remained significant in Ethiopia.

\section{Changes in FGC-related behaviour}

\section{Future intention to continue the practice with one's daughters}

The intervention period was 18 to 21 months and no changes in behaviour were anticipated, i.e., actual cutting of girls, in such a short time period. Therefore, a proxy indicator was chosen to measure if change was beginning to occur, by asking respondents whether they intended to cut their daughters in the future.

There were significant shifts in the future intention to not cut their daughters as indicated in Figure 2.8. Only a small proportion of respondents expressed an intention not to cut their daughters during the baseline survey, in both Kenya and Ethiopia. In Kenya, these proportions remained low even at the time of the endline survey, while in Ethiopia they increased significantly in the intervention site (325\%) compared to the control site (-7\%). In Kenya, apart from the baseline survey, there was no significant difference between intervention and comparison site respondents in their intention to not cut their daughters in the future. However, the change from baseline to endline survey in the comparison site in Kenya was statistically significant $(\mathrm{P}<.001)$. 


\section{FIGURE 2.8 Proportions of respondents who do not intend to cut their daughters in the future in Ethiopia and Kenya}

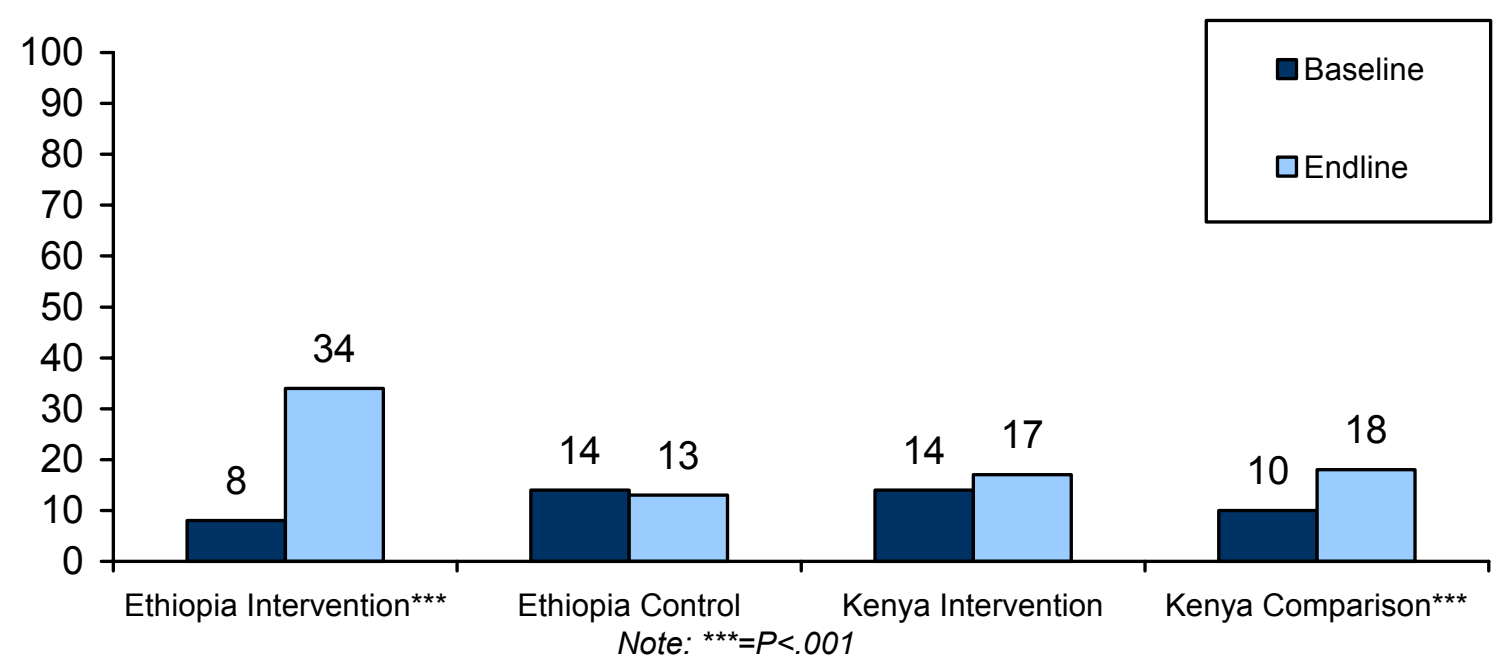

The views of men and women differed. In Ethiopia, men (32\%) were significantly more likely to express the intention not to cut their daughters in the future than women (16\%) during the endline survey. In Kenya, there was a slight reduction in the proportion of women expressing this view both in the intervention and comparison sites, whereas for men, there was an increase and the magnitude of change was higher among men from the comparison $(213 \%)$ than the intervention (46\%) site.

Expression of intention not to cut their daughters in the future was significantly associated with education and exposure to anti-FGC messages both in Ethiopia and in Kenya during the baseline and endline surveys. Respondents who had primary and above levels of education and those who had heard anti-FGC messages were more likely to express the view that they did not intend to cut their daughters in the future. In Ethiopia, it was only during the endline survey that age had a significant association. While in Kenya, both during the baseline and endline surveys, age and marital status were significantly associated with this indicator.

Never married respondents in Kenya were significantly more likely to report not intending to cut their daughters. The age relationship, although significant, did not show any clear pattern in Ethiopia or Kenya.

Multiple regression analysis controlling for the effect of these socio-demographic and antiFGC exposure variables reveals that the observed site differences cease to be significantly associated with the intention not to cut their daughters in the future. As Annex 2, Table A2.5 indicates, differences in education, exposure to anti-FGC messages and time of survey remain significant both in Ethiopia and in Kenya, while gender is significant only in Ethiopia and age only in Kenya. Respondents with primary and above levels of education are 2 and 1.8 times, while respondents who have heard anti-FGC messages are 10.6 and 2.4 times more likely to intend not to cut their daughters in the future in Ethiopia and Kenya respectively.

Respondents aged 15-24 years and 25-34 years in Kenya were more likely to intend not to cut their daughters in the future than those aged above 44 years.

During the baseline survey, respondents who said that they intended to cut their daughters in the future were asked to name the type of cut they intended for their daughters. In Kenya, the proportion intending to practice infibulation on their daughters in the future was significantly higher in the intervention (44\%) compared to the comparison (33\%) site. Unfortunately, this question was not asked during the endline survey in Kenya or during both surveys in Ethiopia. 


\section{SUMMARY, CONCLUSIONS, AND RECOMMENDATIONS}

\section{Did the Interventions go According to Plan?}

Given the sensitivities around discussions of a taboo subject, entry into the community worked with a minimum level of negative reaction. Staff and volunteers proceeded cautiously and respectfully to introduce the theme of FGC abandonment. The project position, publicly spoken, was that while the project staff of CARE and its partner agencies did not believe that the practice should continue, it was ultimately the communities' decision on whether the practice should continue or not. A critical first entry step was awareness raising that targeted local leaders and elders. The entry was aided by the fact that reproductive health activities were already operating prior to this project and communities already trusted and respected the CARE staff. The project staff and volunteers' roles in the intervention as trusted facilitators of a community process - and later as negotiators and supporters for those deciding to end the practice - is perceived as critical in allowing the project to go as far as it did in terms of fostering change on the issue.

Education and advocacy interventions were implemented mostly as planned. In Ethiopia, because CARE was introducing FGC abandonment activities for the first time, it was easier to control the interventions than in Kenya. The major focus of advocacy efforts in Ethiopia was working with religious leaders, which occurred early in the project intervention period and resulted in a consensus by many leaders that FGC was not a religious obligation. Community education outreach only began around the ninth month, because of the time taken to develop the educational outreach messages. Given the more traditional Afar culture, the concepts of rights and responsibilities to ensure the good health and social well being of girls and women were addressed through gender equity actions and not educational messages in the intervention sites, e.g., ensuring female representation on committees and as outreach workers - "firsts" in that community. The main factor that led to contamination between the intervention and control sites was the Dagu system. Messages passed between the Afar and resulted in both sites receiving the interventions, although the change effect remained significantly greater in intervention sites for the most part.

In Kenya, where anti-FGC education and abandonment activities had already been introduced at a low level in three refugee camps by NCCK before the intervention began, it was more difficult to control the education and advocacy activities occurring in the intervention and comparison camps. While for the most part, intervention activities through a variety of channels occurred as planned, there were several instances of unequal application of the interventions that led to contamination between the intervention and comparison sites and the mixed and less pronounced results found in Kenya (compared to Ethiopia). For example, several religious leaders -already reached by CARE/NCCK outreach prior to this project continued to advocate for an end to the practice in the comparison camp. The resulting effect was exacerbated when planned work with local religious leaders to develop a consensus on the position of Islam on FGC and to ask them to work as advocates never occurred, and so religious leaders continued to provide mixed messages to the faithful in both camps.

The participatory educational theatre (PET) groups had been in existence before the interventions and continued to play active roles in the comparison site (from which many of the group members originated), but were less active in the intervention camp. Rights issues were addressed directly and vigorously in education activities in Kenya because the context was very different than that found in Ethiopia. Women's rights campaigns were already ongoing in the camps prior to the intervention and the refugees themselves were already aware of refugee conventions and their rights. There was also evidence that work on human 
rights in the comparison camp of Hagadera was more active than the intervention camp (Ifo), because the Project Officer resided in that camp.

\section{Did the Interventions Result in Expected Increases in Knowledge, Attitude and Intended Behavior Indicators?}

Improvements in knowledge. After an intervention period of 18-21 months, the findings indicate that the interventions were effective in increasing knowledge of harmful effects of FGC in Ethiopia and Kenya. Although people were more likely to recall messages about health than about rights, social, or psychosexual issues, knowledge gains in all four areas indicated that all types of messages were being heard. The magnitude of change in knowledge of harmful effects between the baseline and endline surveys was significantly higher in the intervention compared to the control/comparison sites in Ethiopia and Kenya, suggesting that the interventions did have a net effect after allowing for other FGC awareness raising activities beyond the project activities. A comparison of the magnitude of change between baseline and endline in Ethiopia and Kenya clearly showed that the intervention in Ethiopia was more effective in increasing knowledge than in Kenya. Although men had higher mean knowledge scores during the baseline in both Kenya and Ethiopia, and during the endline survey in Ethiopia, increases in knowledge were higher among females than males both in Ethiopia and in Kenya. This is probably because with exposure to new information, and as the group experiencing the negative effects of FGC directly, women would now associate some effects they had initially not associated with FGC.

Addressing underlying but related issues of gender and rights in relation to the practice. Although Ethiopia adopted a different strategy from Kenya in introducing FGC as a rights issue, the interventions led to an increase in the proportion of respondents who viewed FGC as a rights issue in both countries. In Ethiopia, the magnitude of change in support of the view that FGC violates the rights of women and of girls was significantly higher in the intervention than the control site. Although there were significant increases in both the intervention and comparison sites in Kenya, the magnitude of change was greater in the comparison than the intervention site. The Ethiopian approach led to a larger magnitude of change in the rights indicators than CARE's model in Kenya. Both in absolute proportions and in the magnitude of change in responses between baseline and endline, more men than women viewed FGC as a rights violation, in both Kenya and Ethiopia.

Similar trends were found in attitude on gender equality indicators. Mean scores on gender equality were significantly higher in the comparison site in Kenya and in the intervention site in Ethiopia, although the magnitude of increase was greater in the intervention than the comparison site in Kenya. Males had significantly higher mean scores compared to women in both Kenya and Ethiopia. In Kenya, men had a significant increase in mean scores while women's mean scores decreased at endline.

Why did this improvement in attitudes occur in Ethiopia, where no direct discussion on rights had occurred, and not in Kenya? This may be due to discussions held with religious leaders on the position of Islam as it related to FGC in Ethiopia. Rights of women were discussed in some of the Sunnas and Hadiths and possibly during the several meetings between religious leaders that were hosted by the project to allow them to come together and develop a consensus on the position of Islam. The FGD facilitator mentioned this point in discussion with religious leaders in Kenya. It could be assumed that religious leaders in Ethiopia used the same references in their deliberations and that rights were part of this deliberation. Or, perhaps discussions of rights were heard from information sources outside of the project. 
Why were men more supportive of the rights of women and girls by endline than women were? No clear reason exists. In discussions on rights held in both countries as the interventions were beginning, men and women cited their rights to good health and to a good life and during probing admitted that women were less likely to achieve their rights than men. Inequality of the sexes was confirmed during these meetings. Thus, a basis of rights already existed in these communities and perhaps the issue of FGC served to raise awareness that women's rights were compromised in men's minds, and this was reflected at the end of the intervention. Social change is not a linear process and perhaps women's responses are a reflection of the gender conflict that started to take place in the communities with public discussions of FGC and rights of women, a situation likely to lead to backlash among the women.

Attitude changes in favour of abandonment of FGC. The observed increases in knowledge about, and attitude in support of, FGC as a rights issue did not translate into increases in support for FGC abandonment in Kenya, as it did in Ethiopia. The magnitude of change in support of FGC abandonment was significantly higher in the Ethiopia intervention site than the control site, while in Kenya the comparison site increased support for FGC abandonment while the intervention site did not change. In Ethiopia, males were significantly more likely to support FGC abandonment than females. Although both men and women increased their support, the magnitude of change was larger amongst men than women in the intervention site. While men in both sites in Kenya increased their support by 22 percent, women decreased theirs by 32 percent.

Intention to not cut their daughters in the future. In Ethiopia, although both the intervention and control sites registered increased intention not to cut their daughters, the intervention site had a significantly higher magnitude of change. However, in Kenya, the results were mixed. The proportions expressing intention not to cut their daughters remained low and even decreased amongst women both in the intervention and comparison sites, and the magnitude of change among men was higher in the comparison than intervention site.

Comparing change in key knowledge and attitude indicators in Ethiopia and Kenya. One could argue that since FGC interventions in Kenya had been going on before the OR study and consequently Kenya was starting at a higher level of knowledge and positive attitudes, it would be unfair to expect as much impact in Kenya as in Ethiopia. In absolute terms, the proportions in Kenya of respondents exposed to anti-FGC messages, who expressed the views that FGC violates the rights of women and girls, had significantly higher mean FGC harmful effects knowledge scores than in Ethiopia at baseline. However, at endline, in absolute terms, the proportions in the Ethiopia intervention site of respondents exposed to anti-FGC messages, who expressed the attitude that FGC violates the rights of women, supported FGC abandonment, and expressed the intention not to cut their daughters in the future had higher mean FGC knowledge scores than the intervention and comparison sites in Kenya. By the endline survey, even FGC abandonment and the intention not to cut their daughters in the future, which were not significantly different at baseline, registered much higher absolute change in percentages in the Ethiopia intervention site than the two sites in Kenya.

Multivariate analyses results indicate that the interventions were not effective in increasing the intention to not cut their daughters in the future. In both Ethiopia and Kenya, the type of site was not significantly associated with the intention not to cut their daughters in the future. However, multivariate analyses confirmed the effectiveness of the interventions in changing other indicators in Ethiopia: the type of site (intervention or comparison) was significantly associated with mean knowledge of harmful FGC effects, the attitude that FGC violates the rights of girls, and support for FGC abandonment, with the intervention site having a higher predictive value. 
In Kenya, although the type of site was significantly associated with the attitude that FGC violates women's and girls' rights and support for FGC abandonment, the comparison site performed better than the intervention site. The reason for this cannot be explained by exposure to anti-FGC messages. The increase in proportion of respondents exposed to antiFGC messages was greater in the intervention (48\%) than in the comparison (-7\%) site and in absolute terms the intervention site had a higher proportion exposed (59\%) compared to the comparison (47\%) site at endline. The difference can partly be attributed to the significant differences in socio-demographic characteristic between the two sites: the comparison site had significantly higher levels of education and lower mean age compared to the intervention site both during the baseline and endline surveys. Education and age were significantly associated with attitudes in support of FGC as a violation of women's and girls' rights and the intention not to cut their daughters in the future. The more educated and younger respondents expressed more positive attitudes than the less educated and older respondents.

In conclusion, the intervention in Ethiopia achieved significant positive change in all knowledge and attitude indicators, whereas the intervention in Kenya did not. Furthermore, women in both countries, but especially in Kenya, were more resistant to change than men. While the community education and advocacy intervention was clearly successful in Ethiopia, it is difficult to conclude that the advocacy strategy was effective in Kenya.

There are several reasons why this may have happened. Firstly, although high proportions of respondents in Kenya cited CARE as the source of their anti-FGC messages, a significantly higher proportion mentioned radio as their main source and for the comparison site, this was the highest single source of anti-FGC messages. It is important to note, however, that radio messages were not always in support of FGC abandonment. Secondly, lower proportions of respondents in Kenya mentioned religious leaders as their source of anti-FGC messages than in Ethiopia. Therefore, it is likely that religious leaders did not fully and positively advocate for FGC abandonment in Kenya as was expected.

The significant increases in knowledge and attitude in support of FGC as a rights issue in Kenya did not translate into increases in support of FGC abandonment and the intention not to cut their daughters in the future. One plausible reason could be the intensity of exposure to the intervention. The proportion of respondents reporting that they were exposed to anti-FGC messages in the Ethiopian intervention site was much higher than in the Kenyan intervention and comparison sites. Both in Ethiopia and in Kenya, it is important to note that multiple logistic regression models underline exposure to anti-FGC messages as a significant predictive factor for supporting FGC abandonment, believing that FGC violates the rights of women and of girls, and intention not to cut their daughters in the future. Therefore, lower levels of exposure to the intervention might translate to lower increases in positive attitudes and intended behaviour. It is also possible that there were other contextual factors in the Kenya refugee camps that were not captured in the quantitative surveys. For example, qualitative data collected during the endline alluded to the possibility of a backlash against the project activities due to the enforcement of the law criminalizing FGC in Kenya during the intervention period. Attempts to enforce this law among some Somali refugee parents, who were discovered to have cut their daughters, enraged the community.

\section{Was Collective Action Against the Practice Beginning to Occur by the End of the Intervention Period?}

Changing practices that are deeply entrenched in the culture and social life of individuals and their communities, such as FGC, requires individuals to identify and acknowledge these practices as problematic, consider their importance, evaluate their own behaviour, attitudes and beliefs, and begin to make changes in their lives. However, since individual behaviour is 
strongly linked to and reinforced by prevailing social norms and belief systems in their community, getting the larger community and those influential people who are charged with upholding social norms to contemplate and question these norms and belief systems is critical to create an enabling environment for individual behaviour change. The "communication for social change" model (Figueroa et al, 2002) acknowledges the inherent limitations of individual change models based on transmission and persuasion precepts, and instead, explicitly links individual change to a larger context of social change. Collectively defined change is needed, through the development of policies and laws, and particularly in community-based interventions, through to fostering of public, gender-equitable dialog and discussion of issues, reinforced by 'permissions' accorded by influential people and leaders in the community, e.g., religious leaders, for individuals to debate a norm within public community settings.

In applying this model to the CARE interventions in Ethiopia and Kenya, it is clear that the belief and attitude changes observed at the individual level were also beginning to be reflected in the collective actions or initial social changes observed at the community level. Before the intervention, there was a small proportion of the population (less than a quarter) that was already privately convinced that it would be good to end the practice of FGC, evidenced by their stated intention to surveyors to not cut their daughters in the future. This was true in both countries: there was no significant difference between Ethiopia and Kenya in the proportions supporting FGC abandonment (approximately 17-18\%) and those planning not to cut their daughters in the future (approximately 11-12\%) at baseline. That this 'radical' but silent group existed in a context of an almost universal practice of cutting is likely due to prior exposure to information and messages that challenged the practice of FGC, including radio messages, and in Kenya, the systematic intervention activities conducted by NCCK in both the intervention and comparison sites. However, the health education interventions implemented prior to the OR study had limited impact. Other catalysts and change agents were needed to take the issue to the public domain, including influential people in communities advocating for change, community dialog to allow public recognition by both women and men of the issue, to clarify perception, values and beliefs around FGC and its health and social consequences, and to allow for different expressions to be heard. This combination of actions helped many people to change their individual beliefs. For some, it encouraged more public actions based upon their evolving belief that change was necessary and based on an increasing sense of self-efficacy, bolstered by the knowledge that others of like mind existed in the community. The project interventions provided new information on social consequences that challenged the value of the practice, its continued relevance, and provided public spaces for collective dialog by women and men of a 'women's issue', in both countries. By endline, in Ethiopia and Kenya (although more pronounced in Ethiopia), there was an increase in the proportion of respondents who expressed support for FGC abandonment and the intention to not cut their daughters in the future.

Anecdotal observations by staff, during their interactions with community members and in focus group discussions held during the endline survey, indicated that many social changes were occurring. First, men and women said that there was much talk about FGC and abandoning the practice or moving to a lesser form - an enormous change when considering how secretive the subject was as the interventions began and that men and women did not discuss such issues together in public settings. In Kenya, there was on-going debate on whether to change or end the practice, with men and women stating that there was still a need to clarify the relation of religion and FGC - that religious leaders themselves were divided on the subject. In Ethiopia, where religion was no longer a critical reason for continuing the practice (as this issue had been addressed successfully during the intervention period), people were discussing how they could end the practice while ensuring that their girls could remain virgins until they were married, a critical reason for continuing the practice in this community. Information on abandoning the practice was being passed through the Dagu 
system, which is used to pass only critical messages that relate to ensuring the larger Afar community's security and well-being.

Such gendered and collective discussions were occurring in social environments that were not yet supportive of change and were tugging at the social cohesion of the communities in question bringing about conflict and social discomfort. Individuals and families were beginning to publicly take positions on ending the practice, although the numbers were small, particularly in Kenya. In Kenya, about six months into the intervention period, some girls and families began to declare themselves against the practice and as a result began to feel great social pressure to stop promoting this idea. Some families felt so threatened that they began to seek asylum with $\mathrm{UNHCR}^{13}$ or came to CARE staff to ask for protection. CARE established several "safe" houses where girls and family members could stay that offered them some level of protection against attacks or abductions for unwanted circumcisions. More proactively, support groups emerged in each camp (supported by CARE). These were named "circles of friends" and had men, women, and girls who were publicly against the practice as members. As the project ended, there were about 50 families in the Ifo and Hagadera circle of friends. In Ethiopia, individuals and families that were publicly stating they were against the practice were also feeling social pressure.

Relations between the sexes were also thought to be changing - in some cases getting more strained than before, as FGC got debated and husbands and wives may have begun to take conflicting views on the need to circumcise their daughters. Community leaders were being brought in to adjudicate conflicts arising between family members regarding circumcising daughters. By the endline survey, the social environment in the Ethiopia intervention site had become more supportive compared to the baseline survey environment. The observed positive changes in Ethiopia led to community action in support of FGC abandonment. About 15 months after collecting endline data, 70 village elders from both the intervention and control sites publicly declared an end to the practice in Afar areas where CARE operated its development and RH programs. Although it is difficult to tell at this stage if the collective actions / public declarations by elders will translate into behaviour change for all members of the affected villages, it is clear that having greater community and gender equitable ownership of an issue with the support of its leadership will have the effect of enhancing a positive societal environment, which in turn may ultimately lead to a change in the social norms around cutting.

This beginning of collective action at the community level poses a new question about what changes should be measured in FGC abandonment projects. If the development of collective action influences or is linked to change in an individual's attitudes towards future intentions to not cut their daughters, how does one monitor and measure collective action in more quantitative ways than ever intended by the current study? This question requires further research.

One final thought on community leadership: The intervention in Ethiopia was more effective than in Kenya in increasing the proportions of respondents willing to challenge the practice, as reflected by the higher increases in Ethiopia at endline in proportions exposed to anti-FGC messages, in knowledge of negative FGC-effects, and in proportions reporting that FGC is a human rights violation issue. Why was the intervention in Ethiopia so successful in bringing about collective action for change after a short period of implementation, while Kenya, which had received quite similar interventions over a much longer period of time, remained resistant to change. The population in the Kenya sites had higher levels of education than Ethiopia, a factor positively associated with FGC knowledge, attitude and intended behaviour indicators, leading to the assumption that there would be greater change in Kenya than in Ethiopia. One

\footnotetext{
${ }^{13}$ Recent rulings by UNHCR allowed refugee girls fleeing "persecution" for their beliefs against FGC to get priority consideration for resettlement to a third country.
} 
factor that appears to have been different between Ethiopia and Kenya was the mobilization of religious leaders in the intervention. Although both groups are of Islamic faith and highly religious, CARE was much more successful in engaging the religious leaders in Ethiopia than in Kenya. Many of these influential leaders in Ethiopia started to speak with one voice on the position of Islam vis-à-vis FGC, themselves becoming a critical mass that could advocate for change and in so doing, give permission to the faithful to discuss and change a practice that no longer was considered relevant for reasons of religion. It is also plausible that the fact that the FGC intervention in Kenya was associated with a Christian group (NCCK) might have raised distrust among the predominantly Islamic group.

\section{Recommendations}

FGC programs should have a strong monitoring and evaluation framework to assist them to identify the key factors that impede or aid progress from one stage of social change to another in the specific socio-cultural and political context and adapt their intervention strategies to address these factors as they go along. For example in Kenya, as a matter of urgency, CARE should endeavor to strengthen the role of the Islamic religious leaders in the intervention sites. To create an enabling environment for consensus on the position of Islam in relation to FGC, it is prudent to invite respected Islamic religious scholars or leaders to dialogue with religious leaders in the intervention sites. In addition to addressing the other knowledge and sociocultural factors, FGC programs implemented in communities that attach a religious significance to the practice cannot afford to leave out religious leaders. Religious leaders should not only be a primary target group, but should also be empowered as implementers and change agents.

The findings of this study show that it is possible to bring about change and more positive FGC abandonment attitudes, even in the context of low educational levels, as seen in Ethiopia. This is true, even when statistically it was seen that education was significantly associated with some attitude and intended behavior indicators, especially in Kenya. Improvement in formal education is likely to contribute to attitude and behavior change in the long run and to change the underlying gender relations between men and women. Other factors that are under the control of program managers and were significantly associated with FGC attitude change are exposure to anti-FGC messages, increase in gender equality attitudes, and knowledge of harmful FGC effects.

Gender differences were critically apparent throughout the study findings and highlight the importance of male involvement in any community-level program working towards FGC abandonment. As seen in the CARE interventions that focused on both men and women, men adopted more positive gender and FGC attitudes compared to women. By creating an enabling environment for dialogue, FGC interventions should encourage communities to think critically about human rights, sexism, gender and social inequalities, and oppression within their specific socio-cultural context.

If organizations are to engage in programming that leads to social change or that challenges social norms, they need to ensure that they can work in a sustained manner with communities. That is, they need to make a commitment to "accompany" communities in a social change process. This is the only ethically justified way to proceed. As the OR intervention period was ending, there was conflict within the communities whether to continue, change, or abandon the practice. There were shifts in thinking about the rights and equality of the sexes. These conflicts were being played out between individuals and couples and within extended families. If FGC abandonment activities had ended with the close of the 18 month study period, the possibility of communities sliding back into their "old" ways or even moving back into more conservative ways - where inequalities get reinforced or people cling to traditions 
that may be no longer valid in their cultures - would be very high. Likewise, if the intervention study period had been longer, we would probably have seen more change in the intention to change the practice of cutting their daughters in the future. 


\section{REFERENCES}

Abdel Hadi, A. 1997. We Are Decided: The Struggle of an Egyptian Village to Eradicate Female Circumcision, Cairo Institute for Human Rights: Cairo, Egypt.

Abdel-Tawab, N. \& S. Hegazi. 2000. Critical Analysis of Interventions Against FGC in Egypt, Population Council: Cairo, Egypt.

Chege, J.N., I. Askew, \& J. Liku. 2001. An Assessment of the Alternative Rites Approach for Encouraging Abandonment of Female Genital Mutilation in Kenya. Population Council, Frontiers in Reproductive Health Study Report.

Figueroa, M.E., D.L. Kincaid, M. Rani, \& G. Lewis. 2002. Communication for Social Change: An Integrated Model for Measuring the Process and Its Outcomes, The Rockefeller Foundation and Johns Hopkins University Center for Communication Programs.

Jones, H., N. Diop, I. Askew, \& I. Kaboré. 1999. "Female Genital Cutting and its negative health outcomes in Burkina Faso and Mali", Studies in Family Planning, 30,3:219-230.

Igras, S.M. 1999. Somaliland Trip Report Notes (referring to RH assessment and priority issues exercises conducted with women attending clinics in the CARE-Somalia Safe Motherhood Project area), CARE-USA.

Igras, S.M., with participation from Aden Abdi, Z.A. Ahmed, T. Kadgu, P. Kilele, J. Kinama, Y. Muhumed, N. Oigo, A. Osman, \& M.B. Yussuf. 1999. Findings from group discussions and exercises to explore issues regarding female genital cutting (FGC): Dagahaley refugee camp in Dadaab, Northeast Kenya. CARE-USA.

Igras, S.M. 2002. Trip Notes: Visit to Dadaab Refugee Camps, 27-28 April 2002 (to undertake exploratory discussions with community groups on rights), CARE USA.

Kambou S. et al. 1998. Draft Report of Findings from Participatory Learning and Action (PLA) Exercises on Key Reproductive Health Issues Facing Women in CARE RH Project Areas in North Kordofan, CARE-USA.

Kambou, S. \& B. Monahan. 1997. The Reproductive Health Awareness and Action Project in Yirowe (RHAAPY) proposal (referring to PLA exercises on priority RH issues for women in Yirowe displaced persons' camp). CARE USA and CARE International in Somalia.

Kenya Demographic and Health Survey 2003: Preliminary Report. Central Bureau of Statistics, Ministry of Health, Kenya Medical Research Institute, Centers for Disease Control and Prevention, Measure DHS ORC Macro.

Morison, L., C. Scherf, G. Ekpo, K. Paine, B. West, R. Coleman, \& G. Walraven. 2001. "The long-term reproductive health consequences of female genital cutting in rural Gambia: A Community-based survey", Tropical Medicine and International Health, 6, 7:1-11.

Nafissatou J. Diop, M.M. Faye, A. Moreau, J. Cabral, H. Benga, F. Cisse, B. Mane, Baumgarten, M. Melching. 2003. Evaluation of a Community Based Education Program in Senegal. Population Council, FRONTIERS Program Report (Forthcoming). 
National Committee on Traditional Practices of Ethiopia (NCTPE). 1998. Final Report of the Baseline Survey on Harmful Traditional Practices in Ethiopia. Addis Ababa.

Nuworo, N. 2003. FGC: Exploring Issues of Social Change and Community Responses to Implementation of Project Activities: Findings from focus group discussions. CARE International in Kenya.

Rainb . 1995. Female Genital Cutting: A Call for Global Action, Rainb $q$, New York, USA.

Tostan. 1999. Breakthrough in Senegal: Ending Female Genital Cutting. Dakar Senegal.

WHO. 1999. Female Genital Mutilation Programmes to Date: What Works and What Doesn't. A Review.

Woldemariam, A. \& J. Muteshi. 2000. FGC in the Awash Afar Region: Findings of a Participatory Learning and Action (PLA) Exercise. CARE International in Ethiopia.

Woldemariam, Asmelash. 2000b. Report on Focus Group Discussions on Rights Issues Among the Afar (draft, 2000).

Woldemariam, Asmelash. 2003. Results of the Focus Group Discussions on FGC abandonment, FGC Operations Research Project, CARE International in Ethiopia. 


\section{ANNEX 1: DESCRIPTION OF KEY ACTIVITIES AND SELECTED OUTPUTS IN ETHIOPIA AND KENYA}

\begin{tabular}{|c|c|c|c|c|}
\hline ETHIOPIA & January-June 2001 & July-December 2001 & January-June 2002 & July-October 2002 \\
\hline Main focus & $\begin{array}{l}\text { - Discussion with community } \\
\text { leaders re the new project and } \\
\text { planned RH and PHC activities } \\
\text { - Baseline qualitative and } \\
\text { quantitative research was } \\
\text { conducted. } \\
\text { - Training, discussion and } \\
\text { consensus on the position of Islam } \\
\text { vis a vis FGC was reached with } 12 \\
\text { local religious leaders. } \\
\text { - Training of staff, project volunteer } \\
\text { health workers, and traditional } \\
\text { health providers. }\end{array}$ & $\begin{array}{l}\text { - Health education and training of } \\
\text { Service Providers to manage FGC } \\
\text { complications. (Training themes } \\
\text { included health complications, } \\
\text { religious obligations, changing } \\
\text { nature of culture (social issues), and } \\
\text { morbidity/ mortality associated with } \\
\text { FGC) } \\
\text { - A multi-disciplinary FGC } \\
\text { abandonment group was formed } \\
\text { (consisting of HC staff, Woreda } \\
\text { Sharia (religious) officials, local } \\
\text { health officials, project extension } \\
\text { agents, trained TBAs and religious } \\
\text { resource persons) to do community } \\
\text { education. } \\
\text { - Education outreach occurred in a } \\
\text { variety of settings and included } \\
\text { evening sessions in all } 29 \\
\text { intervention villages. }\end{array}$ & $\begin{array}{l}\text { - This period was at the height of the } \\
\text { drought and was a life and death } \\
\text { situation for animals and the Afar } \\
\text { people. Little was done on project } \\
\text { activities. Relief activities occurred } \\
\text { instead. } \\
\text { - A facility assessment of health } \\
\text { provider knowledge, skills, and a } \\
\text { supplies and equipment audit } \\
\text { occurred in facilities in intervention } \\
\text { area. } \\
\text { - Some training was conducted. } \\
\text { - Educational outreach also occurred } \\
\text { in different community settings. }\end{array}$ & $\begin{array}{l}\text { Focus on winding down project and } \\
\text { conducting endline survey (October) } \\
\text { and endline FGD research } \\
\text { (September/October) }\end{array}$ \\
\hline $\begin{array}{l}\text { Training } \\
\text { efforts - } \\
\text { Number } \\
\text { reached }\end{array}$ & $\begin{array}{l}\text { - Number trained: } 77 \\
\text { Pastoral health workers (28), Ministry } \\
\text { of Health officials (6), Traditional } \\
\text { birth attendants (26), Local religious } \\
\text { leaders (12), Extension agents (3), } \\
\text { CARE Awash PHC officer (1), CARE } \\
\text { POP-AIDS project training officer (1) }\end{array}$ & $\begin{array}{l}\text { - Number trained: } 319 \\
\text { Refresher training for Pastoral health } \\
\text { workers (28), trained TBAs ( } 33) \text {, } \\
\text { extension agents (3), MOH field staff } \\
\text { (6) } \\
\text { Basic training of religious leaders } \\
\text { (58), elders (68), Enena-Haba } \\
\text { (traditional police) (25) } \\
\text { Youth peer educators (98 boys and } \\
\text { girls) }\end{array}$ & $\begin{array}{l}\text { - Number trained: } 73 \\
\text { Untrained TBAs (12) } \\
\text { Trained TBAs - refresher (45) } \\
\text { Project and MOH staff (BCC) (16) }\end{array}$ & $\mathrm{N} / \mathrm{A}$ \\
\hline
\end{tabular}




\begin{tabular}{|c|c|c|c|c|}
\hline $\begin{array}{l}\text { Educational } \\
\text { outreach \& } \\
\text { advocacy } \\
\text { efforts - } \\
\text { Number } \\
\text { reached }\end{array}$ & - Number reached: None & $\begin{array}{l}\text { - Number reached: } 6,549 \\
\text { Groups reached by the project } \\
\text { directly or by the multi-disciplinary } \\
\text { group included men, boys, girls, and } \\
\text { women. } \\
\text { Indirectly, through the Dagu system, } \\
\text { estimated several thousand were } \\
\text { reached }\end{array}$ & $\begin{array}{l}\text { - Number reached: } 6,366 \\
\text { Groups reached by project directly } \\
\text { and/or MOH staff, religious leaders, } \\
\text { and/or other volunteers included } \\
\text { men, women. }\end{array}$ & N/A \\
\hline KENYA & January-June 2001 & July-December 2001 & January-June 2002 & July-October 2002 \\
\hline Main focus & $\begin{array}{l}\text { - Training and educational outreach } \\
\text { activities occurred. Training themes } \\
\text { included health effects of FGC, } \\
\text { women's, girls', and RH rights, other } \\
\text { social and psychological effects of } \\
\text { FGC. } \\
\text { - Discussions held with first round of } \\
\text { religious leaders (18) selected in the } \\
\text { main Mosques in Ifo } \\
\text { - (Qualitative and quantitative } \\
\text { baseline research had been } \\
\text { conducted prior to this period.) }\end{array}$ & $\begin{array}{l}\text { - Similar focus of activities with } \\
\text { education of specific groups as well } \\
\text { as general educational outreach } \\
\text { occurring. } \\
\text { - New community committees were } \\
\text { formed on the rights of the child (one } \\
\text { per camp). One of its activities was } \\
\text { to focus on protection of girls from } \\
\text { FGC. } \\
\text { - Extension workers (40) in all } \\
\text { camps were trained as TOTs. } \\
\text { - Mass media activities also } \\
\text { occurred, e.g., "16 days of activism } \\
\text { on rights of women and girls" (which } \\
\text { included FGC themes). } \\
\text { - PETs started addressing FGC } \\
\text { related themes in all } 3 \text { camps. } \\
\text { - Advocacy efforts continued. }\end{array}$ & $\begin{array}{l}\text { - Training activities increased } \\
\text { - Educational activities increased } \\
\text { (including PET events.) New } \\
\text { venues were added, including food } \\
\text { distribution sites and home visits. } \\
\text { - Media efforts continued with FGC } \\
\text { themes treated during international } \\
\text { women and refugee day events. } \\
\text { - Advocacy activities were more } \\
\text { organized. An advocacy group in Ifo } \\
\text { was formed with influential people } \\
\text { including block and section leaders, } \\
\text { anti-violence committee members, } \\
\text { religious leaders, and ex- } \\
\text { circumcisers. These people were } \\
\text { actively engaged in public speaking } \\
\text { and home visits. } \\
\text { - The Circle of Friends support } \\
\text { groups were formed (one per camp). }\end{array}$ & $\begin{array}{l}\text { - The first arrest for FGC violation } \\
\text { occurred of a father in Hagadera } \\
\text { camp (the first in the camps since } \\
\text { the Kenyan law went into effect). } \\
\text { There was lots of tension } \\
\text { everywhere, and this occurred } \\
\text { during the endline survey period } \\
\text { (which began in August). } \\
\text { - Training, educational outreach and } \\
\text { advocacy activities continued. } \\
\text { - A 5-day FGC abandonment } \\
\text { campaign was held (no counts } \\
\text { done). } \\
\text { - Anti-FGC committee activities were } \\
\text { extended from home visits to block } \\
\text { discussions and discussions in } \\
\text { Mosques. } \\
\text { - The "Circle of Friends" support } \\
\text { groups' membership increased. }\end{array}$ \\
\hline
\end{tabular}




\begin{tabular}{|c|c|c|c|c|}
\hline $\begin{array}{l}\text { Training } \\
\text { efforts - } \\
\text { Number } \\
\text { reached }\end{array}$ & $\begin{array}{l}- \text { Number trained: } \mathbf{5 5 4} \\
\text { Youth (68), community leaders (64), } \\
\text { TBAs (91), youth leaders/CDWs (27) }\end{array}$ & $\begin{array}{l}\text { - Number trained: } 454 \\
\text {-Women leaders (15), religious } \\
\text { leaders (6), male leaders (14) trained } \\
\text { in advocacy and Members of Action } \\
\text { for the rights of the child (15) } \\
\text {-Extension workers in both camps } \\
\text { trained in TOT ( } 24 \text { women and men } \\
\text { in FGC/GBV, rights, community } \\
\text { mobilization, M\&E) } \\
\text {-Other groups trained were extension } \\
\text { workers, community leaders, youth } \\
\text { leaders (380) }\end{array}$ & $\begin{array}{l}\text { - Number trained: } 399 \\
\text {-Advocacy group members of Ifo (35) } \\
\text {-Others trained were project staff, } \\
\text { volunteers (89) } \\
\text {-Influential people such as religious } \\
\text { leaders (59), other opinion leaders } \\
\text { (80), ex-practitioners and } \\
\text { practitioners (143) }\end{array}$ & - Number trained: 0 \\
\hline $\begin{array}{l}\text { Educational } \\
\text { outreach \& } \\
\text { advocacy } \\
\text { efforts* }\end{array}$ & $\begin{array}{l}\text { - Number reached: } 12,283 \\
\text {-Groups reached included girls, } \\
\text { women, and men. }\end{array}$ & $\begin{array}{l}\text { - Number reached: } 1,985 \\
\text {-Groups included men and women in } \\
\text { general education at community } \\
\text { centres, health facilities, others. }\end{array}$ & $\begin{array}{l}\text { - Number reached: } 15,380 \\
\text {-Home visits (15,254) } \\
\text {-Outreach to groups such as youth, } \\
\text { girls, and women (126) }\end{array}$ & - Number reached: 4,861 \\
\hline
\end{tabular}

* (NB: Estimates not available for Participatory Educational Theatre attendance 


\section{ANNEX 2: Multivariate ANAlysis TABLES}

TABLE A2.1 Results of the multiple linear regression model for mean knowledge scores of all harmful FGC effects in Ethiopia and Kenya

\begin{tabular}{|c|c|c|c|c|}
\hline \multicolumn{5}{|l|}{ Variable } \\
\hline & \multirow[t]{2}{*}{ Beta } & \multirow[t]{2}{*}{$\mathbf{T}$} & \multicolumn{2}{|c|}{$95 \% \mathrm{Cl}$ for $\mathrm{B}$} \\
\hline & & & Lower & Upper \\
\hline \multicolumn{5}{|l|}{ ETHIOPIA } \\
\hline Time - Baseline & .353 & $15.518^{* * *}$ & 2.288 & 2.950 \\
\hline Site - Intervention & -.147 & $-6.598 * * *$ & -1.415 & -.766 \\
\hline Sex - female & -.097 & $-4.419 * * *$ & -1.034 & -.398 \\
\hline Age & -.014 & -.621 & -.013 & .007 \\
\hline Education-none & .082 & $3.615^{* * *}$ & .356 & 1.201 \\
\hline Heard anti-FGC & .210 & $8.804^{* * *}$ & 1.285 & 2.022 \\
\hline \multicolumn{5}{|l|}{ KENYA } \\
\hline Time - Baseline & .445 & $27.795^{* * *}$ & 2.484 & 2.861 \\
\hline Site - Intervention & .030 & 1.868 & -.009 & .368 \\
\hline Sex - female & -.068 & $-4.192 * * *$ & -.599 & -.217 \\
\hline Age & -.020 & -1.114 & -.012 & .003 \\
\hline Education - none & .082 & $4.521^{* * *}$ & .289 & .732 \\
\hline Heard anti-FGC & .213 & $12.913^{* * *}$ & 1.086 & 1.475 \\
\hline
\end{tabular}


TABLE A2.2 Results of the multiple logistic regression model for the attitude that FGC violates rights of women in Ethiopia and Kenya

\begin{tabular}{|c|c|c|c|c|c|c|}
\hline Variable & & B & S.E. & EXP B & $\begin{array}{l}95 \% \mathrm{Cl} \\
\text { Lower }\end{array}$ & $\begin{array}{l}\text { for B } \\
\text { Upper }\end{array}$ \\
\hline \multicolumn{7}{|l|}{ ETHIOPIA } \\
\hline $\begin{array}{l}\text { Intervention }(n=807) \\
\text { Control }(n=812)\end{array}$ & $\begin{array}{l}25 \% \\
14 \% \text { Ref }\end{array}$ & -.239 & .162 & .788 & .573 & 1.083 \\
\hline $\begin{array}{l}\text { Female }(n=820) \\
\text { Male }(n=799)\end{array}$ & $\begin{array}{l}11 \% \\
28 \% \text { Ref }\end{array}$ & 1.311 & .166 & $3.709^{* * *}$ & 2.678 & 5.137 \\
\hline $\begin{array}{l}\text { No Education }(n=1297) \\
\text { Primary+ }(n=302)\end{array}$ & $\begin{array}{l}16 \% \\
35 \% \text { Ref }\end{array}$ & .733 & .187 & $2.081^{* * *}$ & 1.442 & 3.002 \\
\hline $\begin{array}{l}\text { No anti-FGC }(n=1078) \\
\text { Heard anti-FGC }(541)\end{array}$ & $\begin{array}{l}07 \% \\
45 \% \text { Ref }\end{array}$ & 2.192 & .173 & $8.955^{* * *}$ & 6.384 & 12.56 \\
\hline $\begin{array}{l}\text { Baseline }(n=819) \\
\text { Endline }(n=800)\end{array}$ & $\begin{array}{l}09 \% \\
30 \% \text { Ref }\end{array}$ & .998 & .170 & $2.713^{* * *}$ & 1.944 & 3.786 \\
\hline $\begin{array}{l}\text { Age Group } \\
\begin{array}{l}\text { 08-14 }(n=280) \\
15-24(n=514) \\
25-34(n=317) \\
35-44(n=279) \\
45+\quad(n=191)\end{array}\end{array}$ & $\begin{array}{l}13 \% \\
20 \% \\
25 \% \\
19 \% \\
25 \% \text { Ref }\end{array}$ & $\begin{array}{l}.386 \\
.202 \\
.090 \\
-.002\end{array}$ & $\begin{array}{l}.305 \\
.251 \\
.261 \\
.280\end{array}$ & $\begin{array}{l}1.471 \\
1.224 \\
1.094 \\
.998\end{array}$ & $\begin{array}{l}.809 \\
.748 \\
.656 \\
.577\end{array}$ & $\begin{array}{l}2.673 \\
2.002 \\
1.824 \\
1.727\end{array}$ \\
\hline \multicolumn{7}{|l|}{ KENYA } \\
\hline $\begin{array}{l}\text { Intervention }(n=1440) \\
\text { Comparison }(n=1440)\end{array}$ & $\begin{array}{l}28 \% \\
34 \% \text { Ref }\end{array}$ & .259 & .090 & $1.295^{\star *}$ & 1.087 & 1.544 \\
\hline $\begin{array}{l}\text { Female }(n=1440) \\
\text { Male }(n=1440)\end{array}$ & $\begin{array}{l}24 \% \\
38 \% \text { Ref }\end{array}$ & .508 & .092 & $1.662^{\star * \star}$ & 1.389 & 1.989 \\
\hline $\begin{array}{l}\text { No Education }(n=1805) \\
\text { Primary+ }(n=1075)\end{array}$ & $\begin{array}{l}23 \% \\
44 \% \text { Ref }\end{array}$ & .560 & .101 & $1.751^{* * *}$ & 1.437 & 2.134 \\
\hline $\begin{array}{l}\text { No anti-FGC }(n=1475) \\
\text { Heard anti-FGC }(n=1405)\end{array}$ & $\begin{array}{l}16 \% \\
47 \% \text { Ref }\end{array}$ & 1.372 & .093 & $3.941^{* * *}$ & 3.285 & 4.729 \\
\hline $\begin{array}{l}\text { Baseline }(n=1440) \\
\text { Endline }(n=1440)\end{array}$ & $\begin{array}{l}26 \% \\
36 \% \text { Ref }\end{array}$ & .467 & .090 & $1.595^{\star * *}$ & 1.338 & 1.901 \\
\hline $\begin{array}{l}\text { Age Group } \\
\qquad \begin{array}{l}15-24(n=1152) \\
25-34(n=606) \\
35-44(n=490) \\
45+(n=632)\end{array}\end{array}$ & $\begin{array}{l}36 \% \\
36 \% \\
28 \% \\
19 \% \text { Ref }\end{array}$ & $\begin{array}{l}-.434 \\
-.527 \\
-.371\end{array}$ & $\begin{array}{l}.171 \\
.147 \\
.154\end{array}$ & $\begin{array}{l}.648^{*} \\
.590^{* * *} \\
.690^{*}\end{array}$ & $\begin{array}{l}.463 \\
.443 \\
.510\end{array}$ & $\begin{array}{l}.906 \\
.787 \\
.934\end{array}$ \\
\hline $\begin{array}{l}\text { Ever married }(n=1898) \\
\text { Never married }(n=982)\end{array}$ & $\begin{array}{l}27 \% \\
39 \% \text { Ref }\end{array}$ & .109 & .137 & 1.115 & .852 & 1.459 \\
\hline
\end{tabular}


TABLE A2.3 Results of the multiple logistic regression model for the attitude that FGC violates rights of girls in Ethiopia and Kenya

\begin{tabular}{|c|c|c|c|c|c|c|}
\hline \multicolumn{2}{|l|}{ Variable } & B & S.E. & EXP B & \multicolumn{2}{|c|}{$\begin{array}{l}95 \% \text { CI for B } \\
\text { Lower Upper }\end{array}$} \\
\hline \multicolumn{7}{|l|}{ ETHIOPIA } \\
\hline $\begin{array}{l}\text { Intervention }(n=807) \\
\text { Control }(n=812)\end{array}$ & $\begin{array}{l}16 \% \\
13 \% \text { Ref }\end{array}$ & .506 & .184 & $1.659^{* *}$ & 1.157 & 2.378 \\
\hline $\begin{array}{l}\text { Female }(n=820) \\
\text { Male }(n=799)\end{array}$ & $\begin{array}{l}06 \% \\
23 \% \text { Ref }\end{array}$ & 1.629 & .194 & $5.099^{* * *}$ & 3.489 & 7.453 \\
\hline $\begin{array}{l}\text { No Education }(n=1297) \\
\text { Primary+ }(n=302)\end{array}$ & $\begin{array}{l}11 \% \\
30 \% \text { Ref }\end{array}$ & .864 & .200 & $2.372^{* * *}$ & 1.603 & 3.509 \\
\hline $\begin{array}{l}\text { No anti-FGC }(n=1078) \\
\text { Heard anti-FGC }(541)\end{array}$ & $\begin{array}{l}05 \% \\
34 \% \text { Ref }\end{array}$ & 2.373 & .203 & $10.731^{* * *}$ & 7.209 & 15.974 \\
\hline $\begin{array}{l}\text { Baseline }(n=819) \\
\text { Endline }(n=800)\end{array}$ & $\begin{array}{l}07 \% \\
22 \% \text { Ref }\end{array}$ & .852 & .192 & $2.344^{* * *}$ & 1.609 & 3.416 \\
\hline $\begin{array}{l}\text { Age Group } \\
\begin{array}{l}\text { 08-14 }(n=280) \\
15-24(n=514) \\
25-34(n=317) \\
35-44(n=279) \\
45+(n=191)\end{array}\end{array}$ & $\begin{array}{l}09 \% \\
14 \% \\
17 \% \\
16 \% \\
19 \% \text { Ref }\end{array}$ & $\begin{array}{l}.523 \\
.377 \\
.414 \\
-.126\end{array}$ & $\begin{array}{l}.340 \\
.270 \\
.284 \\
.296\end{array}$ & $\begin{array}{l}1.686 \\
1.458 \\
1.513 \\
.881\end{array}$ & $\begin{array}{l}.865 \\
.858 \\
.867 \\
.494\end{array}$ & $\begin{array}{l}3.286 \\
2.475 \\
2.640 \\
1.573\end{array}$ \\
\hline \multicolumn{7}{|l|}{ KENYA } \\
\hline $\begin{array}{l}\text { Intervention }(n=1440) \\
\text { Comparison }(n=1440)\end{array}$ & $\begin{array}{l}28 \% \\
34 \% \text { Ref }\end{array}$ & .299 & .089 & $1.349^{* *}$ & 1.132 & 1.607 \\
\hline $\begin{array}{l}\text { Female }(n=1440) \\
\text { Male }(n=1440)\end{array}$ & $\begin{array}{l}26 \% \\
36 \% \text { Ref }\end{array}$ & .335 & .091 & $1.399^{* * *}$ & 1.170 & 1.672 \\
\hline $\begin{array}{l}\text { No Education }(n=1805) \\
\text { Primary+ }(n=1075)\end{array}$ & $\begin{array}{l}23 \% \\
44 \% \text { Ref }\end{array}$ & .517 & .101 & $1.678^{* * *}$ & 1.377 & 2.043 \\
\hline $\begin{array}{l}\text { No anti-FGC }(n=1475) \\
\text { Heard anti-FGC }(n=1405)\end{array}$ & $\begin{array}{l}16 \% \\
47 \% \text { Ref }\end{array}$ & 1.361 & .093 & $3.900^{* * *}$ & 3.252 & 4.678 \\
\hline $\begin{array}{l}\text { Baseline }(n=1440) \\
\text { Endline }(n=1440)\end{array}$ & $\begin{array}{l}26 \% \\
36 \% \text { Ref }\end{array}$ & .629 & .090 & $1.875^{\star * *}$ & 1.573 & 2.237 \\
\hline $\begin{array}{l}\text { Age Group } \\
\begin{array}{l}15-24(n=1152) \\
25-34(n=606) \\
35-44(n=490) \\
45+(n=632)\end{array}\end{array}$ & $\begin{array}{l}37 \% \\
36 \% \\
27 \% \\
18 \% \text { Ref }\end{array}$ & $\begin{array}{l}-.481 \\
-.535 \\
-.330\end{array}$ & $\begin{array}{l}.170 \\
.147 \\
.155\end{array}$ & $\begin{array}{l}.618^{\star *} \\
.586^{\star * *} \\
.719^{\star}\end{array}$ & $\begin{array}{l}.443 \\
.439 \\
.530\end{array}$ & $\begin{array}{l}.863 \\
.781 \\
.975\end{array}$ \\
\hline $\begin{array}{l}\text { Ever married }(n=1898) \\
\text { Never married }(n=982)\end{array}$ & $\begin{array}{l}27 \% \\
40 \% \text { Ref }\end{array}$ & .194 & .136 & 1.214 & .929 & 1.586 \\
\hline
\end{tabular}


TABLE A2.4 Results of the multiple logistic regression model for the attitude in support of FGC abandonment in Ethiopia and Kenya

\begin{tabular}{|c|c|c|c|c|c|c|}
\hline Variable & & B & S.E. & EXP B & $\begin{array}{l}95 \% \mathrm{Cl} \\
\text { Lower }\end{array}$ & $\begin{array}{l}\text { for B } \\
\text { Upper }\end{array}$ \\
\hline \multicolumn{7}{|l|}{ ETHIOPIA } \\
\hline $\begin{array}{l}\text { Intervention }(n=807) \\
\text { Control }(n=812)\end{array}$ & $\begin{array}{l}38 \% \\
20 \% \text { Ref }\end{array}$ & -.526 & .141 & $.591^{* * *}$ & .448 & .780 \\
\hline $\begin{array}{l}\text { Female }(n=820) \\
\text { Male }(n=799)\end{array}$ & $\begin{array}{l}26 \% \\
32 \% \text { Ref }\end{array}$ & .186 & .140 & 1.204 & .915 & 1.586 \\
\hline $\begin{array}{l}\text { No Education }(n=1297) \\
\text { Primary+ }(n=302)\end{array}$ & $\begin{array}{l}24 \% \\
49 \% \text { Ref }\end{array}$ & 1.135 & .172 & $3.112^{* * *}$ & 2.221 & 4.361 \\
\hline $\begin{array}{l}\text { No anti-FGC }(n=1078) \\
\text { Heard anti-FGC }(541)\end{array}$ & $\begin{array}{l}12 \% \\
62 \% \text { Ref }\end{array}$ & 2.109 & .143 & $8.243^{* * *}$ & 6.222 & 10.920 \\
\hline $\begin{array}{l}\text { Baseline }(n=819) \\
\text { Endline }(n=800)\end{array}$ & $\begin{array}{l}18 \% \\
39 \% \text { Ref }\end{array}$ & .526 & .143 & $1.693^{* * *}$ & 1.278 & 2.242 \\
\hline $\begin{array}{l}\text { Age Group } \\
\qquad \begin{array}{l}08-14(n=280) \\
15-24(n=514) \\
25-34 \quad(n=317) \\
35-44 \quad(n=279) \\
45+\quad(n=191)\end{array}\end{array}$ & $\begin{array}{l}24 \% \\
25 \% \\
42 \% \\
25 \% \\
32 \% \text { Ref }\end{array}$ & $\begin{array}{l}.413 \\
.484 \\
-.222 \\
.244\end{array}$ & $\begin{array}{l}.265 \\
.231 \\
.236 \\
.253\end{array}$ & $\begin{array}{l}1.511 \\
1.622^{*} \\
.801 \\
1.277\end{array}$ & $\begin{array}{l}.898 \\
1.032 \\
.504 \\
.777\end{array}$ & $\begin{array}{l}2.543 \\
2.549 \\
1.272 \\
2.097\end{array}$ \\
\hline \multicolumn{7}{|l|}{ KENYA } \\
\hline $\begin{array}{l}\text { Intervention }(n=1440) \\
\text { Comparison }(n=1440)\end{array}$ & $\begin{array}{l}23 \% \\
15 \% \text { Ref }\end{array}$ & -.557 & .099 & $.573^{* * *}$ & .472 & .695 \\
\hline $\begin{array}{l}\text { Female }(n=1440) \\
\text { Male }(n=1440)\end{array}$ & $\begin{array}{l}16 \% \\
22 \% \text { Ref }\end{array}$ & .371 & .099 & $1.449^{* * *}$ & 1.194 & 1.759 \\
\hline $\begin{array}{l}\text { No Education }(n=1805) \\
\text { Primary+ }(n=1075)\end{array}$ & $\begin{array}{l}19 \% \\
19 \% \text { Ref }\end{array}$ & -.016 & .114 & .985 & .788 & 1.231 \\
\hline $\begin{array}{l}\text { No anti-FGC }(n=1475) \\
\text { Heard anti-FGC }(n=1405)\end{array}$ & $\begin{array}{l}18 \% \\
20 \% \operatorname{Ref}\end{array}$ & .069 & .100 & 1.071 & .881 & 1.303 \\
\hline $\begin{array}{l}\text { Baseline }(n=1440) \\
\text { Endline }(n=1440)\end{array}$ & $\begin{array}{l}17 \% \\
21 \% \text { Ref }\end{array}$ & .246 & .097 & $1.279^{*}$ & 1.057 & 1.549 \\
\hline $\begin{array}{l}\text { Age Group } \\
\qquad \begin{array}{l}15-24(n=1152) \\
25-34 \quad(n=606) \\
35-44 \quad(n=490) \\
45+(n=632)\end{array}\end{array}$ & $\begin{array}{l}20 \% \\
18 \% \\
17 \% \\
20 \% \text { Ref }\end{array}$ & $\begin{array}{l}-.069 \\
.074 \\
.185\end{array}$ & $\begin{array}{l}.139 \\
.151 \\
.159\end{array}$ & $\begin{array}{l}.934 \\
1.077 \\
1.203\end{array}$ & $\begin{array}{l}.711 \\
.801 \\
.880\end{array}$ & $\begin{array}{l}1.226 \\
1.447 \\
1.645\end{array}$ \\
\hline
\end{tabular}


TABLE A2.5 Results of the multiple logistic regression model for the intention not to cut their daughters in the future in Ethiopia and Kenya

\begin{tabular}{|c|c|c|c|c|c|c|}
\hline \multicolumn{2}{|l|}{ Variable } & B & S.E. & EXP B & $\begin{array}{l}95 \% \mathrm{CI} \\
\text { Lower }\end{array}$ & $\begin{array}{l}\text { Ifor B } \\
\text { Upper }\end{array}$ \\
\hline \multicolumn{7}{|l|}{ ETHIOPIA } \\
\hline $\begin{array}{l}\text { Intervention }(n=568) \\
\text { Control }(n=606)\end{array}$ & $\begin{array}{l}25 \% \\
14 \% \text { Ref }\end{array}$ & -.314 & .189 & .731 & .505 & 1.058 \\
\hline $\begin{array}{l}\text { Female }(n=601) \\
\text { Male }(n=573)\end{array}$ & $\begin{array}{l}15 \% \\
24 \% \text { Ref }\end{array}$ & .659 & .186 & $1.932^{* * *}$ & 1.341 & 2.784 \\
\hline $\begin{array}{l}\text { No Education }(n=919) \\
\text { Primary+ }(n=250)\end{array}$ & $\begin{array}{l}15 \% \\
33 \% \text { Ref }\end{array}$ & .767 & .208 & $2.153^{* * *}$ & 1.433 & 3.235 \\
\hline $\begin{array}{l}\text { No anti-FGC }(n=756) \\
\text { Heard anti-FGC }(418)\end{array}$ & $\begin{array}{l}06 \% \\
42 \% \text { Ref }\end{array}$ & 2.367 & .213 & $10.66^{\star * \star}$ & 7.027 & 16.18 \\
\hline $\begin{array}{l}\text { Baseline }(n=417) \\
\text { Endline }(n=757)\end{array}$ & $\begin{array}{l}11 \% \\
23 \% \text { Ref }\end{array}$ & .555 & .238 & $1.742^{*}$ & 1.092 & 2.780 \\
\hline $\begin{array}{l}\text { Age Group } \\
\begin{array}{l}\text { 08-14 }(n=273) \\
15-24(n=480) \\
25-34(n=169) \\
35-44(n=126) \\
45+(n=98)\end{array}\end{array}$ & $\begin{array}{l}19 \% \\
17 \% \\
24 \% \\
14 \% \\
29 \% \text { Ref }\end{array}$ & $\begin{array}{l}-.484 \\
.126 \\
.310 \\
.757\end{array}$ & $\begin{array}{l}.353 \\
.314 \\
.328 \\
.387\end{array}$ & $\begin{array}{l}.617 \\
1.134 \\
1.363 \\
2.131\end{array}$ & $\begin{array}{l}.309 \\
.613 \\
.716 \\
.998\end{array}$ & $\begin{array}{l}1.231 \\
2.097 \\
2.594 \\
4.551\end{array}$ \\
\hline \multicolumn{7}{|l|}{ KENYA } \\
\hline $\begin{array}{l}\text { Intervention }(n=1440) \\
\text { Comparison }(n=1440)\end{array}$ & $\begin{array}{l}16 \% \\
14 \% \text { Ref }\end{array}$ & -.196 & .110 & .822 & .663 & 1.019 \\
\hline $\begin{array}{l}\text { Female }(n=1440) \\
\text { Male }(n=1440)\end{array}$ & $\begin{array}{l}13 \% \\
16 \% \text { Ref }\end{array}$ & .079 & .113 & 1.082 & .868 & 1.349 \\
\hline $\begin{array}{l}\text { No Education }(n=1805) \\
\text { Primary+ }(n=1075)\end{array}$ & $\begin{array}{l}10 \% \\
22 \% \text { Ref }\end{array}$ & .593 & .125 & $1.810^{* * *}$ & 1.418 & 2.310 \\
\hline $\begin{array}{l}\text { No anti-FGC }(n=1475) \\
\text { Heard anti-FGC }(n=1405)\end{array}$ & $\begin{array}{l}08 \% \\
22 \% \text { Ref }\end{array}$ & .912 & .118 & $2.489^{* * *}$ & 1.974 & 3.139 \\
\hline $\begin{array}{l}\text { Baseline }(n=1440) \\
\text { Endline }(n=1440)\end{array}$ & $\begin{array}{l}12 \% \\
17 \% \text { Ref }\end{array}$ & .401 & .110 & $1.493^{* * *}$ & 1.202 & 1.853 \\
\hline $\begin{array}{l}\text { Age Group } \\
\qquad \begin{array}{l}15-24(n=1152) \\
25-34(n=606) \\
35-44(n=490) \\
45+(n=632)\end{array}\end{array}$ & $\begin{array}{l}19 \% \\
16 \% \\
10 \% \\
09 \% \text { Ref }\end{array}$ & $\begin{array}{l}-.447 \\
-.369 \\
.021\end{array}$ & $\begin{array}{l}.210 \\
.186 \\
.210\end{array}$ & $\begin{array}{l}.639^{*} \\
.692^{\star} \\
1.021\end{array}$ & $\begin{array}{l}.424 \\
.480 \\
.677\end{array}$ & $\begin{array}{l}.966 \\
.997 \\
1.540\end{array}$ \\
\hline $\begin{array}{l}\text { Ever married }(n=1898) \\
\text { Never married }(n=982)\end{array}$ & $\begin{array}{l}12 \% \\
20 \% \text { Ref }\end{array}$ & .064 & .163 & 1.066 & .775 & 1.466 \\
\hline
\end{tabular}

